
NBSIR $84-2810$

PERFORMANCE EVALUATION OF

TELEPHONE CABLE PEDESTALS IN

UNDERGROUND AND ATMOSPHERIC

ENVIRONMENTS

J. L. Fink and E. Escalante

U.S. DEPARTMENT OF COMMERCE

National Bureau of Standards

Center for Materials Science

Metallurgy Division

Washington, DC 20234

January 1984

Sponsored by:

Department of Agriculture

Rural Electrification Administration

Washington, DC 20250

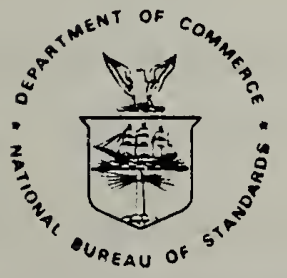

U.S. DEPARTMENT OF COMMERCE, Malcolm Baldrige, Secretary NATIONAL BUREAU OF STANDARDS, Ernest Ambler, Director 



\title{
PERFORMANCE EVALUATION OF TELEPHONE CABLE PEDESTALS IN UNDERGROUND AND ATMOSPHERIC ENVIRONMENTS
}

\author{
J. L. Fink and E. Escalante \\ Corrosion Group, Metallurgy Division \\ National Bureau of Standards \\ Washington, DC 20234
}

\section{INTRODUCTION}

The installation of telephone cable pedestals by the telephone industry has increased to the degree that reliable information is needed on their performance in underground and atmospheric environments. In order to obtain such data, the National Bureau of Standards and the Rural Electrification Administration initiated a six-year study of the durability of a variety of telephone cable pedestals. The program was started in 1977 with the exposure of five pedestal systems in selected underground and atmospheric environments. In 1979 a sixth pedestal system was added to the program. This report contains the results obtained for the pedestals exposed at the National Bureau of Standards test sites for up to six years.

\section{ENVIRONMENTS AT THE TEST SITES}

The chemical and physical properties of the soils at the test sites are given in table 2. The chemical properties listed show that the soils differ widely with respect to their composition and the concentration of soluble salts. The $\mathrm{pH}$ of the soils ranges from extreme acidity (4.0) to high alkaijnity (8.8). The electrical resistivity of the soils varies from $55 \mathrm{ohm}-\mathrm{cm}$, which is approximately that of sea water, to $30,000 \mathrm{ohm}-\mathrm{cm}$. Well aerated and poorly aerated soils are included in the study. 
These widely differing soil environments allow for a comprehensive underground corrosion program. The soils included are moderately corrosive (Sites $B$ and $H$ ) to very corrosive (Sites C, G, and I) toward ferrous and other metals. Descriptions of the environments at the six test sites are as follows:

Sagemoor sandy loam (Site A) is a well-drained alkaline soil and is typical of that found in vast areas of eastern Washington and Oregon. The site is located on the Yakima Indian Reservation near Toppenish, Washington. The soil is consistent in composition to a depth of at least seven feet and supports abundant growth of sage brush.

The average annual sunshine at this site is 2,600 hours, the average annual precipitation is 8 in. $(20.3 \mathrm{~cm})$, and the average annual humidity is 63\%. The average annual temperature of $90{ }^{\circ} \mathrm{F}\left(32^{\circ} \mathrm{C}\right)$ and above totaled 30 days, while the average annual temperature of $32^{\circ} \mathrm{F}\left(0{ }^{\circ} \mathrm{C}\right)$ and below totaied 120 days.

Hagerstown loam (Site B) is a well-drained soil representative of the majority of well developed soils found in the eastern part of the United States. The site is located at the Loch Raven Reservoir of the Baltimore City Water Department. The soil consists of a brown loam about one foot deep, underlain by a reddish-brown clay that extends five feet or more to underlying rock. Practically all of the materials that have been investigated in the extensive NBS underground corrosion tests since 1922 have been exposed at this site and, therefore, it can serve as a reference site for the correlation of data obtained for specimens in the present program with data obtained from the earlier tests.

The average annual sunshine at this site is 2,600 hours, the average annual precipitation is $40 \mathrm{in.}(102.4 \mathrm{~cm})$, and the average annual humidity is $70 \%$. The average annual temperature of $90{ }^{\circ} \mathrm{F}\left(32^{\circ} \mathrm{C}\right)$ and above totaled 30 days, while the average annual temperature of $32^{\circ} \mathrm{F}\left(0{ }^{\circ} \mathrm{C}\right)$ and below totaled 120 days. 
Clay soil (Site C). This site is located approximately 100 yards $(91.4 \mathrm{~m})$ from the ocean shore in a large clay pit on level land at the U. S. Coast Guard Receiving Center at Cape May, New Jersey. The soil consists of a plastic gray clay to a depth of twelve inches. This is underlain by a poorly drained, very heavy plastic clay to which the specimens are exposed.

The average annual sunshine at this site is 2,600 hours, the average annual precipitation is $40 \mathrm{in} .(102.4 \mathrm{~cm})$, and the average annual humidity is 73\%. The average annual temperature of $90{ }^{\circ} \mathrm{F}\left(32^{\circ} \mathrm{C}\right)$ and above totaled 10 days, while the average annual temperature of $32{ }^{\circ} \mathrm{F}\left(0^{\circ} \mathrm{C}\right)$ and below totaled 60 days.

Tidal Marsh (Site G) is a soil typical of the poorly-drained marsh soils that are found along the Atlantic and Gulf coasts and is charged with hydrogen sulfide. The site is located approximately 200 yards (182.8m) from the Chesapeake Bay shore along a creek that empties into the Chesapeake Bay at Lexington Park, Maryland on the property of the U.S. Naval Air Training Center.

The average annual sunshine at this site is 2,600 hours, the average annual precipitation is 40 in. $(102.4 \mathrm{~cm})$, and the average annual humidity is 70\%. The average annual temperature of $90^{\circ} \mathrm{F}\left(32^{\circ} \mathrm{C}\right)$ and above totaled 30 days, while the average annual temperature of $32^{\circ} \mathrm{F}\left(0^{\circ} \mathrm{C}\right)$ and below totaled 60 days. Wooster loam (Site $\mathrm{H}$ ) is a well drained soil found in the mountain regions of New York and Pennsylvania. The soil consists of a brownish-yellow loam with no hardpan. This site was choosen for the very cold temperatures which occur in winter. The site is located at a telephone microwave tower station in Mehoopany, Pennsylvania.

The average annual sunshine at this site is 2,400 hours, the average annual precipitation is 40 in. $(102.4 \mathrm{~cm})$, and the average annual humidity is $75 \%$. The average annual temperature of $90{ }^{\circ} \mathrm{F}\left(32{ }^{\circ} \mathrm{C}\right)$ and above totaled 10 days, while the average annual temperature of $32^{\circ} \mathrm{F}\left(0^{\circ} \mathrm{C}\right)$ and below totaled 150 days. 
Norfolk sand (Site I) is a white, loose sand that supports an abundant growth of beach grasses. This site was chosen for the warm temperatures which occur generally year long. The site is located approximately 100 yards ( $91.4 \mathrm{~m}$ ) from the ocean shore in a well drained nearly level area on the property of a residential development at Murrel's Inlet, South Carolina. The area is not subject to overflow from the ocean except under unusual flood conditions.

The average annual sunshine at this site is 3,000 hours, the average annual precipitation is $48 \mathrm{in} .(121.9 \mathrm{~cm})$, and the average annual humidity is 83\%. The average annual temperature of $90^{\circ} \mathrm{F}\left(32^{\circ} \mathrm{C}\right)$ and above totaled 50 days, while the average annual temperature of $32^{\circ} \mathrm{F}\left(0^{\circ} \mathrm{C}\right)$ and below totaled 10 days.

\section{MATERIALS}

The buried telephone cable pedestals used in this study were of two categories. The first category was a channel-type pedestal which resembled a rectangular column as illustrated in figure 1 . Pedestals of this type were constructed of fiberglass or painted galvanized steel. These pedestals were assembled with stainless or galvanized steel bolts and supported by either a fiberglass, painted galvanized, or unpainted galvanized steel mounting stake. The second category was a dome-type pedestal which resembled a cylindrical column, as shown in figure 2. Pedestals of this category were fabricated of fiberglass and polyvinylchloride (PVC). The cover plate of the pedestals was constructed of fiberglass, while the integrated back plate and mounting stake (manufactured as one piece) was constructed of polyvinylchloride.

All the pedestals used several types of materials for securing the internal components to the pedestal housing. These components were fabricated from stainless steel, aluminum, plated steel, and galvanized steel. 
The final two systems in this report were mounting stakes, the type of mounting stake exposed with one of the channel-type pedestal systems.

Table 1 describes the various types of pedestal and mounting stake systems included in this report.

\section{TEST PROCEDURES}

In order to expose the telephone cable pedestals to the environment, assembly was necessary as shown in figures 1 and 2 . Specimens of systems 1 through 4 and 6 were constructed of several parts, starting with the pedestal back plate which was fastened to a mounting stake with mounting stake bolts. Then the electrical connecting assembly was secured to the back plate by the mounting stake bolts or other hardware. The electrical connecting assembly was divided into four parts; the electrical connector, the electrical connector to bracket securing hardware, the bracket, and the bracket to back plate securing hardware. After the electrical connector assembly was secured to the back plate, the ground cover plate and the cover plate could be placed into position and fastened by the locking retainer assembly. Specimens of system 5 consisted of a cover plate and an integrated mounting stake and back plate cover as shown in figure 2. An insulated support strap clipped into the mounting stake and back plate cover. The electrical connecting assembly was fastened to the insulated support strap by the manufacturer. Finally, the cover plate was positioned over the insulated support strap and secured in place by locking studs and the locking retainer assembly which were located on the integrated mounting stake and back plate cover. Systems 7 and 8 were only mounting stakes as shown in figure 3 . System 8 was electrically coupled to a zinc bar by mechanically bonding the bar to an electrical wire which was in turn bolted to 
the mounting stake. Coupling the mounting stake to zinc thus created a gaivanic cell.

Six pedestals of each system were exposed at each of the test sites. Except for systems 7 and 8 the specimens were exposed in a trench excavated to a depth of approximately three to four feet $(0.9$ to $1.2 \mathrm{~m})$ so the mounting stake and pedestal could be placed into position for burial. The pedestals were spaced approximately three feet $(0.9 \mathrm{~m})$ apart. All pedestals were buried to the depth of the ground level line which was indicated on the ground cover plate at approximately six inches $(15 \mathrm{~cm}$ ) above the bottom edge of the ground cover plate. Only systems 7 and 8 were buried by driving the mounting stake into the soil with a sledge hammer.

Each year a replicate specimen was withdrawn from each of the test sites for cleaning and examination.

Nine regions of each pedestal were examined and rated numerically for corrosion resistance in accordance with table 3 . These regions were the cover plate, cover plate cap, back plate above and below ground, ground cover plate above and below ground, mounting stake above and below ground, and mounting stake bolts. Changes in the color of the pedestals were also noted. In addition, four regions of hardware parts consisting of rivets, screws, and bolts located on the cover plate, cover plate cap, back plate, and ground cover plate were rated in accordance with table 3 as were the electrical connecting assembly, locking retainer assembly, and the warning sign.

\section{RESULTS}

The results obtained from the evaluation of the pedestals for periods up to six years in various underground and atmospheric environments are summarized in tables 4 through 15 . It should be noted that at the time of 
this report pedestals of Site $A$ had not been recovered since the underground and atmospheric removals of 1978. Specimens of System 6 were exposed two years after the installation of Systems 1 through 5, which limited the results for that system to only four years of exposure. Pedestals of System 6 that were to be recovered at Sites $B, C$, and $G$ for the third year removal and at Sites $H$ and $I$ for the second and third year removals were not recovered at those times. These pedestals were recovered with the fourth year exposure specimens and rated as part of the fourth year removal. Pedestals of Systems 1 through 5 designated to be recovered for the fifth year removal at Sites $B, C$, and $G$ were not recovered at that time. The same was true at Site $H$ for the fourth and fifth year exposure specimens and at Site I for the third, fourth, and fifth year exposure specimens. These pedestals were recovered with the sixth year exposure specimens and were rated as part of the sixth year removal. Specimens of each system with varying degrees of corrosion on metallic surfaces and degradation of fiberglass surfaces are shown in figures 5 through 22.

As previously noted, regions of the pedestals were given numerical ratings to indicate the extent of corrosion to metallic surfaces and degradation to fiberglass surfaces. These ratings are described in table 3 . A rating of ten indicates that the pedestal was unaffected by corrosion or degradation while a rating of zero indicates severe corrosion or degradation sufficient to permit dust and sunlight to enter the pedestal. The various systems and their performance in the six underground and atmospheric environments in which the pedestals were exposed are described below.

System 1. This system consisted of a fiberglass channel type pedestal secured to a fiberglass mounting stake. Mounting stake bolts were of stainless steel, and the pedestal hardware was of stainless steel, aluminum, and plated brass material. 
There was no degradation of the fiberglass surface on specimens of this system exposed for one year at Sites $A, C, G$, and $H$ and for three years at Site $B$. The specimens exposed at sites $H$ and $I$ for six years indicated slight degradation on the outside of the fiberglass cover plate. Slight to moderate degradation on the outside of the fiberglass cover plate cap was noted on the specimens exposed at sites $B, C, G, H$, and I for six years. The specimens exposed at Sites $B, H$, and I for six years showed slight degradation of the fiberglass surface on the outside of the back plate above ground level. slight cracking on the outside of the back plate above ground level was noted on the specimens at all sites exposed for six years.

The fiberglass mounting stake on specimens of this system indicated slight degradation above ground level at Sites $H$ and $I$ after exposure for six years.

The color of the pedestal was slightly lighter than that of the original color after exposure for six years at sites $C, G, H$, and I.

There was little or no corrosion of the pedestal hardware after exposure for one year at Site $A$, for up to three years at Site $B$, and for up to six years at Site $H$. Slight dissipation due to corrosion was noted on the plated brass connector plate on specimens at Sites B, C, G, and I after exposure for six years. The specimens exposed at Sites $C$ and $G$ for six years showed slight pitting on the connector plate to bracket hardware (an aluminum alloy rivet). slight pitting was observed on the aluminum alloy bracket of specimens at Sites B, C, G, and I after exposure for six years.

The warning sign on specimens of this system exposed for six years at Sites $C, H$, and I was slightly less legible than that of the original warning sign. The warning sign was separating from the pedestal at Site $B$ after exposure for six years. 
All pedestals of this system were delivered to the National Bureau of Standards with the fiberglass surface cracked on the inside of the specimens at the rounded corners of the cover plate and the ground cover plate.

System 2. This system consisted of a fiberglass channel type pedestal secured to an unpainted galvanized steel mounting stake. The mounting stake bolts were of a stainless steel, and the pedestal hardware was of stainless steel, aluminum, and plated steel and brass material.

The pedestals exposed for one year at Sites $A, B, G$, and $H$ showed little or no degradation of the fiberglass surface. Varying degrees of degradation were noted on the outside of the fiberglass cover plate, cover plate cap, and the back plate above ground level of specimens exposed for two, three, four and six years at Sites B, C and G. However, the most severe degradation was observed on the same regions after exposure for six years at site $H$ and on the cover plate and cover plate cap after exposure for six years at Site I.

The unpainted galvanized steel mounting stake showed little or no corrosion after exposure for six years at Sites $H$ and I. Slight attack was observed on the galvanized steel surface of the mounting stake below ground level after six years of exposure at Site $B$, while slight dissipation and pitting was noted on the mounting stake after exposure for six years at Site C. Pitting due to corrosion of $0.001 \mathrm{in}$. to $0.005 \mathrm{in}$. and rust stain was found on the mounting stake below ground level after six years of exposure at Site G.

The color of the pedestal was considerably lighter than that of the original color and was not glossy after exposure for two, three, four and six years at Site $B$, for up to six years at Site $C$, for four and six years at Site $G$, for three and six years at site $H$, and for six years at site $I$.

In general, superficial or no corrosion was observed on the pedestal hardware on specimens of this system exposed for two years at Site $B$ and for 
six years at Site $H$. The specimens exposed at site $C$ for two, three, four and six years, Site G for three, four and six years, and Site I for one, two, and six years showed slight localized pitting on the inside of the pedestal on the aluminum alloy hardware of the cover plate cap. Slight pitting due to corrosion was noted on the aluminum alloy rivets of specimens on the inside of the back plate above ground level after exposure at Site G for up to six years. Varying degrees of corrosion were noted on the steel clip of the locking retainer assembly on the inside of the pedestal exposed for four and six years at Sites $B$ and $C$ and for six years at Site $H$ with the most severe corrosion on the specimens exposed for six years at Sites $G$ and I.

The aluminum alloy warning sign of specimens of this system showed slight pitting after exposure for one through six years at all test sites. The warning sign was slightly less legible than the original sign after exposure for six years at Sites $B$ and $G$.

System 3. This system consisted of a painted galvanized steel channel type pedestal secured to a painted galvanized steel mounting stake. The mounting stake bolts were galvanized steel, and the pedestal hardware was of stainless steel, plated steel and plated brass material.

There was little or no corrosion of the painted galvanized steel surface on specimens of this system after exposure for one year at Sites A, B, H, and I. The specimens exposed at Sites $B$ and $H$ for two, three, and six years and at Site $G$ for up to six years exhibited blistering of the paint on the galvanized surface on the outside of the cover plate cap at the area adjacent to the stainless steel rivets. However, specimens exposed at Site $C$ for six years and at Site I for one, two and six years indicated blistering of the paint at the area adjacent to the stainless steel rivets on the inside and outside of the cover plate cap. The painted galvanized steel surface on the outside of 
the back plate and ground cover plate on specimens below ground level showed blistering of the paint at the area adjacent to the stainless steel rivets at Site B after exposure for six years. Varying degrees of corrosion were noted on the painted galvanized steel surface on the inside and outside of the back plate and ground cover plate below ground level at Sites $C$ and $G$ after exposure for up to six years. The most severe corrosion was observed on the specimen at Site $G$ after exposure for six years indicating slight dissipation of the galvanized steel surface where the paint had deteriorated from the surface of the back plate and ground cover plate above ground level. However, the same specimen examined at the same areas but below ground level exhibited dissipation of the galvanized steel surface with rust stain of 25 to 50 percent over that surface and pitting due to corrosion of 0.005 in. to 0.010 in.

The painted galvanized steel mounting stake on specimens of this system was unaffected by corrosion at Site $B$ above ground level and at Site $H$ above and below ground level after exposure for six years. Blistering of the paint on the mounting stake was noted on the specimens at Sites $C$ and I above ground level and at Sites B and I below ground level after exposure for six years. Perforation due to corrosion was observed on the mounting stake below ground level for the specimen exposed at Site G for six years.

The color of the pedestals was considerably lighter than that of the original color at all sites after exposure for six years. The color of the specimens at Sites $G$ and I exposed for six years was observed as semi-glossy, while the specimens at site $C$ exposed for six years showed no gloss.

There was little or no corrosion on the pedestal hardware of this system exposed for one year at Site $A$ and for two years at Sites $B$ and $H$. Specimens exposed for three, four, and six years at site B, for up to six years at Site C, for four and six years at site G, and for one, two and six years at Site I 
exhibited slight dissipation of the plating material on the plated brass connector plate. The plated steel bracket showed slight dissipation of the plated steel surface at Site B after exposure for two, three, four, and six years, while the plated steel bracket indicated corrosion and rust stain covering approximately 10 to 25 percent of the bracket surface at Sites C, G, and I after exposure for six years. The plated steel clip on the inside of the locking retainer assembly showed pitting due to corrosion of 0.001 in. to 0.005 in. at Sites B, C, H, and I after exposure for six years while the plated steel clip of the locking retainer assembly was severely corroded and considered destroyed at Site $G$ after exposure for six years.

The warning sign on specimens of this system was slightly less legible at Sites $G, H$, and I exposed for six years.

System 4. This system consisted of a painted galvanized steel channel type fedestal secured to a painted galvanized steel mounting stake. Mounting stake bolts were of galvanized steel, and the pedestal hardware was of stainless steel, galvanized steel, and plated brass material. There was little or no corrosion of the painted galvanized steel surface for specimens of this system after exposure for one year at Sites $A$ and $H$ and for four years at Site B. Specimens exposed for six years at Sites $C$ and $H$ and for two, three, four, and six years at Site G showed blistering of the paint on the galvanized steel outside surface of the cover plate adjacent to the stainless steel rivets, while the specimen exposed for six years at Site I exhibited blistering of the paint on the inside and outside of the cover plate adjacent to the stainless steel rivets. The painted galvanized steel back plate and ground cover plate above ground level exhibited blistering of the paint after exposure for six years at Sites $C$ and I. However, the back plate and ground cover plate below ground level of the same specimens showed slight attack of the galvanized steel surface where the paint had deteriorated from the surface. Blistering of the 
paint on the galvanized steel surface was observed on the outside of the back plate above and below ground level and for the ground cover plate below ground level for specimens exposed at Site $H$ for six years. Specimens exposed at Site $G$ for four and six years exhibited dissipation of the painted galvanized steel surface on the inside of the back plate and ground cover plate below ground level. The same areas of the same specimens developed rust stain over 25 to 50 percent of the galvanized steel surfaces and pitting due to corrosion of 0.005 in. to $0.010 \mathrm{in}$.

The painted galvanized steel mounting stake on specimens' of this system below ground level exhibited pitting of $0.001 \mathrm{in}$. to $0.010 \mathrm{in}$. at Sites $C$ and $G$ after exposure for six years. The galvanized steel mounting bolts showed slight corrosion of the galvanized surface on the inside and outside of the pedestals at Sites B, C, H, and I after exposure for six years. However, dissipation and rust stain were indicated on the mounting stake bolts below ground level on specimens at Site $G$ after exposure for six years.

The color of the pedestal at Site $H$ exposed for six years was uneffected, while the color of the pedestals at Sites B, C, G, and I was slightly lighter than that of the original color after exposure for six years.

There was little or no corrosion of the pedestal hardware for specimens of this system at Sites $A$ and $C$ after exposure for one year and at Sites B, G, and $\mathrm{H}$ for exposure up to two years. The stainless steel rivets on the inside of the cover plate, cover plate cap, and back plate above ground level showed slight pitting and rust stain due to corrosion at Site $B$ after exposure for six years. At site $C$ the stainless steel rivets indicated slight pitting and rust stain on the back plate above ground level after four and six years of exposure. Of the specimens exposed at Sites $G$ and $I$, all areas examined on the pedestals exhibited superficial to slight rust staining and/or pitting after exposure for up to six years. Slight dissipation due to corrosion of the plated material 
was observed on the plated brass connector plate for specimens exposed at Site $B$ for three, four, and six years and at sites $C, G, H$, and I for up to six years. The connector plate to bracket hardware (a stainless steel material) exhibited only superficial or no corrosion at Sites B, G, and $H$ after six years of exposure. Slight attack was noted on the galvanized steel bracket on specimens at Sites $C, G, H$, and I after exposure for six years.

The warning sign for specimens of this system exposed for six years at Sites $C, G$, and $H$ were considerably lighter in color than that of the original color. However, the warning sign exposed for six years at Site I was not legible and was considered unsatisfactory.

System 5. This system consisted of a fiberglass and polyvinylchloride (PVC) dome type pedestal. The fiberglass cover plate was secured to a PVC integrated back plate and mounting stake. Mounting bolts (studs) were of an aluminum alloy. Pedestal hardware was of stainless steel, aluminum, and plated brass materials.

The outside of the fiberglass cover plate of specimens exposed for six years at Sites $B, C$, and $G$ were considerably lighter in color than that of the original, while the cover plate of specimens exposed for the same amount of time at Sites $\mathrm{H}$ and I were significantly lighter in color. The outside surface of the fiberglass cover plate of these specimens after six years of exposure at all sites exhibited extrusion marks.

The fiberglass cover plate was very difficult to remove from the polyvinylchloride intergrated back plate and mounting stake at Sites $C, G, H$ and I after six years of exposure.

The intergrated back plate and mounting stake could not be installed in the ground by driving the mounting stake with a sledge hammer at Sites $B, C$, $H$, and I. A trench had to be excavated before these specimens could be installed at these sites. 
With few exceptions the pedestal hardware of this system was noted as having superficial or no corrosion. The steel rivets on the outside of the fiberglass cover plate cap of the specimens exposed for four and six years at Site $B$, six years at Site $H$, and one, two, and six years at Site I exhibited localized pitting due to corrosion from 0.001 in. to 0.005 in. in depth. The same hardware on the fiberglass cover plate cap of the specimens exposed for four and six years at Site $C$ and six years at Site $G$ showed severe pitting of 0.010 in. to 0.020 in. Slight dissipation was noted on the plated brass connector plate of the specimen exposed for six years at Site G. The connector plate to bracket hardware (a plated steel screw) showed rust and slight pitting due to corrosion on the specimens exposed for two, three, four, and six years at Site B. Slight pitting was observed on the aluminum alloy bracket of the specimens exposed for three, four and six years at Sites $B$ and $C$ and for six years at Site $G$. The bracket to back plate hardware (an aluminum alloy stud) exhibited slight pitting after exposure for four and six years at Site C. Slight pitting and rust stain was noted on the outside of the stainless steel locking retainer assembly of the specimen exposed for six years at Site G.

The warning signs of the pedestals were only slightly lighter in color than that of the original after six years of exposure.

System 6. This system consisted of a fiberglass channel type pedestal secured to an unpainted galvanized steel mounting stake. The mounting stake bolts were of stainless steel material, and the pedestal hardware was of stainless steel, aluminum, and plated brass materials.

Specimens of this system were exposed for only four years at Sites B, C, $G, H$, and $I$.

Except for specimens of this system exposed at Sites $C$ and $G$, there was no degradation of the fiberglass surface on any of the pedestals exposed for up to two years. Slight degradation was noted on the outside of the fiber- 
glass cover plate cap on specimens exposed for two years at Sites $C$ and $G$, while moderate degradation was observed on the fiberglass surface of the back plate exposed for two years at Site $C$. The specimens at Sites $C, H$, and I showed slight to moderate degradation on the outside of the fiberglass cover plate after exposure for four years. Slight degradation was exhibited on the outside of the fiberglass ground cover plate and back plate above ground level for specimens exposed for four years at Site I, while slight degradation was noted on the back plate above ground level after the same exposure time at Site $C$.

The galvanized steel mounting stake below ground level showed slight attack and rust staining due to corrosion after four years of exposure at Site $C$, while the mounting stake at site $G$ exhibited dissipation and rust staining over ten to twenty five percent on the galvanized steel surface.

With few exceptions, the pedestal hardware of this system was noted as having superficial or no corrosion after exposure for up to two years at sites $B, G$, and $H$. The aluminum alloy hardware on the inside of the cover plate cap exhibited slight pitting on the specimens exposed at site $C$ for two years and at Site I for one and four years. Slight attack of the plated brass connector plate was noted on specimens at Sites B, C, H and I exposed for four years. The aluminum alloy bracket on pedestals of this system developed slight pitting at Sites C, G and I after exposure for four years. Slight pitting and rust staining due to crevice corrosion was observed on the stainless steel locking retainer assembly on the inside of specimens at Sites $C$ and $G$ after exposure for two and four years.

In general, the aluminum alloy warning sign on specimens of this system was uneffected by corrosion at all sites after exposure for four years.

System 7. This system consisted of only a painted galvanized steel mounting stake, the same type of mounting stake secured to the pedestals of 
System 4. Specimens of this system were exposed at Site G only.

The region above ground level of the specimen exposed for four years at this site showed slight blistering of the paint on the galvanized steel surface. The region below ground level of the same specimen indicated corrosion of the galvanized steel surface with rust areas occuring over 10 to 25 percent of the mounting stakes surface. Slight dissipation was noted on the region above ground level on the specimen exposed for six years, while rust areas were noted over 25 to 50 percent on the galvanized steel surface below ground level on the same specimen.

System 8 . This system was the same as System 7 except that the painted galvanized steel mounting stake was coupled to a zinc anode. Specimens of this system were exposed at Site G only.

The painted galvanized steel mounting stake exposed at this site for six years developed blistering of the painted surface at the region above ground leve1. However, the same specimen showed slight dissipation of the galvanized steel surface at the region below ground level.

The zinc anode after six years of exposure had approximately 10 percent of the original mass remaining.

\section{DISCUSSION}

The data presented describe the performance of various pedestal systems after exposure for up to six years in different underground and atmospheric environments. Six (6) different pedestal systems and two (2) mounting stake systems (using fiberglass, polyvinylchloride (PVC), painted and unpainted galvanized steel, stainless steel, aluminum, plated steel and plated brass materials) were investigated under some very adverse conditions. 
Six underground and atmospheric environments were employed which have chemical and physical properties representative of a wide range of environments that may be encountered in the United States in actual field installations. Some are moderately corrosive and some are very corrosive towards ferrous and other metals or alloys. Some environments are very cold and others are extremely hot and humid.

The data show that of the systems exposed for up to six years, few were resistant to corrosion of the metal surfaces or to degradation of the fiberglass surfaces in all of the environments in which they were exposed.

The performance of System * 1 after exposure for one year was excellent in an alkaline soil. Degradation due to sunlight and moisture of the fiberglass pedestal housing after exposure for six years in Hagerstown loam, Wooster loam, and Norfolk sand was observed as fair, while the pedestal housing exposed in clay soil and tidal marsh was rated as poor. The performance of the mounting stake, mounting stake bolts, and the color of the pedestal exposed for one year in an alkaline soil and six years in Hagerstown loam, clay soil, tidal marsh, Wooster loam, and Norfolk sand was excellent to very good.

The pedestal hardware, electrical hardware assembly, and the locking retainer assembly on specimens exposed in all environments for six years, showed little or no corrosive attack. The performance of the warning sign on specimens of System 1 exposed in an alkaline soil for one year and in clay soil, tidal marsh, Wooster loam, and Norfolk sand for six years was excellent to very good. However, the condition of the warning sign on the specimen exposed in Hagerstown loam for six years was rated as poor.

\footnotetext{
*Systems are described in Table 1.
} 
The performance of System 2 after exposure for one year was excellent in an alkaline soil. The fiberglass pedestal housing on specimens of this system exposed for six years in Hagerstown loam, clay soil, and tidal marsh was rated as fair, while the pedestal housing exposed for six years in Wooster loam and Norfolk sand was rated as poor due to degradation of the fiberglass surface. The condition of the mounting stake was excellent to very good in hagerstown loam, Wooster loam and Norfolk sand after exposure for six vears, while the condition of the mounting stake was good to fair in clay soil and tidal marsh after the same length of time. The mounting stake bolts of specimens exposed for six years in all environments were rated as excellent. However, the color of the pedestals exposed for six years in all environments was observed as poor. The condition of the pedestal hardware and warning sign was generally excellent to very good after exposure for six years in all environments. The same was true for the electrical hardware assembly after exposure for the same length of time, except for the electrical hardware assembly exposed in a tidal marsh which was rated as fair. The performance of the locking retainer assembly on specimens exposed for six years in Hagerstown loam and Wooster loam was noted as very good to good, while the locking retainer assembly exposed for the same length of time in clay soil, tidal marsh and Norfolk sand was observed as poor.

System 3 was uneffected by corrosion after exposure for one year in an alkaline soil. The condition of the pedestal housing on specimens of this system exposed in Hagerstown loam, clay soil, Wooster loam, and Norfolk sand for six years was noted as very good to good, while that of the companion specimens exposed in a tidal marsh was rated as poor. The corrosion resistance of the mounting stake on specimens in Hagerstown loam, clay soil, Wooster loam, and Norfoik sand was very good to good after exposure for six years, while the mounting stake in tidal marsh was observed as very poor after being exposed for the same length of time. The performance of the mounting 
stake bolts on specimens in Hagerstown loam, clay soil, Wooster loam, and Norfolk sand was excellent to very good after exposure for six years, while the mounting stake bolts in a tidal marsh were rated as good after being exposed for some length of time. The color of the specimens after exposure for six years in Hagerstown loam and Wooster loam was observed as excellent to good. However, the color on specimens exposed for the same length of time in clay soil, tidal marsh, and Norfolk sand was noted as poor. The condition of the pedestal hardware and the warning sign on specimens was shown to be excellent to very good after exposure for six years in all soil and atmospheric environments. The performance of the electrical hardware assembly was observed as excellent to very good after exposure for six years in Hagerstown loam and Wooster loam. However, the electrical hardware assembly was noted as good to fair after being exposed for the same length of time in clay soil, tidal marsh, and Norfolk Sand. The corrosion resistance of the locking retainer assembly was fair to poor in Hagerstown loam, clay soil, Wooster loam, and Norfolk sand after exposure for six years, while the locking retainer assembly was very poor in a tidal marsh after the same length of time.

Specimens of System 3 and 4 were designed with a plastic lightning shield which was attached to the inside of the pedestal. The shield was uneffected in all of the soil and atmospheric environments after exposure for six years. The plastic fasteners on these specimens which were used to help secure the shield to the pedestal, were slightly brittle on the outside of the pedestal after being exposed for the same length of time.

System 4 was uneffected by corrosion after being exposed for one year in an alkaline soil. The performance of the pedestal housing on specimens exposed for six years in Hagerstown loam, clay soil, Wooster loam, and Norfolk sand was considered very good to good, while the pedestal housing exposed for the same length of time in a tidal marsh was rated as poor. The corrosion 
resistance of the mounting stake on specimens of this system in Hagerstown loam and Wooster loam after exposure for six years was observed as very good. However, the performance of the mounting stake in clay soil, tidal marsh, and Norfolk sand exposed for the same length of time was rated as good to fair. In general, the condition of the mounting stake bolts and the color of the pedestals exposed for six years in all the soil and atmospheric environments were observed as excellent to very good. The pedestal hardware, electrical hardware assembly and locking retainer assembly on specimens of System 4 after exposure for six years in all soil and atomospheric environments were noted as excellent to very good. The condition of the warning sign on specimens in Hagerstown loam after six years of exposure was very good, while that of companion specimens in clay soil, tidal marsh, and Wooster loam were rated as poor. However, the condition of the warning sign in Norfolk sand exposed for six years was rated as very poor, and considered unsatisfactory.

The performance of System 5 after exposure for one year was excellent in an alkaline soil. The condition of the pedestal housing, mounting stake, and mounting stake bolts on specimens of this system exposed for six years in all soil and atmospheric environments was excellent. The color of the pedestal was noted as good after exposure for six years in Hagerstown loam, clay soil, and tidal marsh. However, the performance of color on companion specimens was rated as poor after being exposed for the same length of time in Wooster loam and Norfolk sand. The performance of the pedestal hardware on specimens exposed for six years in Hagerstown loam, Wooster loam, and Norfolk sand was rated as fair, while the performance of the pedestal hardware exposed for the same length of time in clay soil and tidal marsh was noted as poor. The condition of the electrical hardware assembly, locking retainer assembly and warning sign was generaily excellent to very good in all soil and atmospheric environments after exposure for six years. 
The performance of the fiberglass pedestal housing of System 6 exposed for four years in Hagerstown loam, clay soil, and tidal marsh was rated as good, while the pedestal housing exposed for the same length of time in Wooster and Norfolk sand was rated as fair.

The corrosion resistance of the mounting stake of specimens exposed for four years in Hagerstown loam, Wooster loam, and Norfolk sand was observed as excellent to very good. The performance of the mounting stakes on companion specimens exposed in clay soil and tidal marsh was noted as good. The corrosion resistance of the mounting stake bolts on specimens of this system after exposure for four years in all soil and atmospheric environments was considered excellent. The color of the pedestal after exposure for four years in Hagerstown loam was rated as very good, while the color after the same length of time in tidal marsh and Norfolk sand was observed as good. However, the performance of the color on specimens exposed for four years in clay soil and Wooster loam was rated as poor. The condition of the pedestal hardware, electrical hardware assembly, locking retainer assembly and warning sign on specimens was generally excellent to very good in all soil and atmospheric environments after exposure for four years. The results for specimens of this system were only available for up to four years of exposure in Hagerstown loam, clay soil, tidal marsh, Wooster loam, and Norfolk sand. Specimens of this system were not exposed in an alkaline soil.

The corrosion resistance of specimens for System 7 exposed for six years was poor in a tidal marsh, while System 8 (same as System 7 but coupled to a zinc anode) exposed for the same length of time was noted as good. The performance of the mounting stake bolts on specimens of System 8 in a tidal marsh after exposure for six years was observed as excellent. Systems 7 and 8 were mounting stakes exposed only in a tidal marsh. 
Areas of specimens that showed relatively poor performance after six years of exposure in one or more of the more aggressive soil and atmospheric environments included the fiberglass pedestal housing above ground level on specimens of System 1 and 2, the painted galvanized steel pedestal housing and mounting stake below ground level on specimens of Systems 3 and 4 , the locking retainer assembly on the inside of specimens of Systems 2 and 3 , the warning sign on System 4 and the steel rivets on the cover plate cap of specimens of System 5 . 
TABLES

Table 1 Description of Various Systems Included in the Evaluation Study of Telephone Cable Pedestals.

Table 2 Properties of Soils at the Test Sites.

Table 3 Rating Code for the Performance Evaluation of Telephone Cable Pedestals

Table 4 Performance of Pedestals Exposed for One Year in Sagemoor Sandy Loam (Site $A$ ).

Table 5 Performance of Pedestal Hardware Exposed for One Year in Sagemoor Sandy Loam (Site A).

Table 6 Performance of Pedestals Exposed up to Six Years in Hagerstown Loam (Site B).

Table 7 Performance of Pedestal Hardware Exposed up to Six Years in Hagerstown Loam (Site B).

Table 8 Performance of Pedestals Exposed up to Six Years in Clay Soil (Site C).

Table 9 Performance of Pedestal Hardware Exposed up to Six Years in Clay Soil (Site C).

Table 10 Performance of Pedestals Exposed up to Six Years in Tidal Marsh (Site G).

Table 11 Performance of Pedestal Hardware Exposed up to Six Years in Tidal Marsh (Site G).

Table 12 Performance of Pedestals Exposed up to Six Years in Wooster Loam (Site $H$ ).

Table 13 Performance of Pedestal Hardware Exposed up to Six Years in Wooster Loam (Site H).

Table 14 Performance of Pedestals Exposed up to Six Years in Norfolk Sand (Site I).

Table 15 Performance of Pedestal Hardware Exposed up to Six Years in Norfolk Sand (Site I). 


\section{FIGURE CAPTIONS}

Figure 1 Various parts of pedestals for Systems 1, 2, 3, 4, and 6 before exposure test.

Figure 2 Various parts of the pedestal for System 5 before exposure test.

Figure 3 Preparation of mounting stakes for Systems 7 and 8 before exposure test.

Figure 4 Systems $1,2,3,4$, and 5 exposed at Site $A$ for one year.

Figure 5 System 1 exposed for six years at Sites B, C, G, H, and I.

Figure 6 System 2 exposed for six years at sites B, C, G, H, and I.

Figure 7 System 3 exposed for six years at Sites B, C, G, H, and I.

Figure 8 System 4 exposed for six years at Sites B, C, G, H, and I.

Figure 9 System 5 exposed for six years at Sites $B, C, G, H$, and $I$.

Figure 10 System 6 exposed for four years at Sites B, C, G, H, and I.

Figure 11 Electrical connector assembly for System 1 exposed for six years at Sites $B, C, G, H$, and $I$.

Figure 12 Electrical connector assembly for System 2 exposed for six years at Sites $B, C, G, H$, and I.

Figure 13 Electrical connector assembly for System 3 exposed for six years at Sites $B, C, G, H$, and $I$.

Figure 14 Electrical connector assembly for System 4 exposed for six years at Sites $B, C, G, H$, and $I$.

Figure 15 Electrical connector assembly for System 5 exposed for six years at Sites B, C, G, H, and I.

Figure 16 Electrical connector assembly for System 6 exposed for four years at Sites $B, C, G, H$, and I.

Figure 17 Cover plate cap of System 1 exposed for six years at Site I.

Figure 18 Back plate of System 1 exposed for six years at Site $H$.

Figure 19 Cover plate cap of System 2 exposed for six years at Site I.

Figure 20 Back plate and ground cover plate of System 3 exposed for six years at Site $G$.

Figure 21 Ground cover plate of System 4 exposed for six years at Site G.

Figure 22 Steel rivet of the cover plate cap of System 5 exposed for six years at site $G$. 
Table 1. Description of Various Systems Included in the Evaluation Study of Telephone Cable Pedestals.

System

Description

1

Fiberglass channel type pedestal, green in color, 4-1/4 in. $x$ $4-1 / 4$ in. $x 36-1 / 4$ in. $(10.80 \mathrm{~cm} \times 10.80 \mathrm{~cm} \times 92.10 \mathrm{~cm})$, with a wall thickness of $0.10 \mathrm{in.}(2.50 \mathrm{~mm})$. Secured to a fiberglass mounting stake, $1-1 / 4$ in. $\times 2$ in. $\times 41$ in. $(3.20 \mathrm{~cm} \times 5.10 \mathrm{~cm} \times$ $104.10 \mathrm{~cm})$, with a wall thickness of $0.15 \mathrm{in} .(3.80 \mathrm{~mm})$. Mounting stake bolts and pedestal hardware were of stainless steel material.

Fiberglass channel type pedestal, green in color, 4 in. $x$ 4 in. $x 34-1 / 2$ in. $(10.20 \mathrm{~cm} \times 10.20 \mathrm{~cm} \times 87.60 \mathrm{~cm})$, with a wall thickness of $0.15 \mathrm{in}$. $(3.80 \mathrm{~mm})$. Secured to an unpainted galvanized steel mounting stake, 1 in. $\times 2-1 / 4$ in. $\times 50$ in. $(2.50 \mathrm{~cm} \times 5.70 \mathrm{~cm} \times 127.0 \mathrm{~cm})$, with a wall thickness of $0.10 \mathrm{in} .(2.50 \mathrm{~mm})$. Mounting stake bolts were of stainless steel material. Pedestal hardware was of stainless steel, aluminum alloy, and plated steel materials.

3. Painted galvanized steel channel type pedestal, green in color, $3-1 / 2$ in. $\times 3-1 / 2$ in. $\times 36-1 / 2$ in. $(8.90 \mathrm{~cm} \times 8.90 \mathrm{~cm}$ $\times 92.70 \mathrm{~cm})$, with a wall thickness of $0.075 \mathrm{in} .(1.90 \mathrm{~mm})$. Secured to a painted galvanized steel mounting stake, 1 in. $x$ 2 in. $x 42$ in. $(2.50 \mathrm{~cm} \times 5.10 \mathrm{~cm} \times 106.70 \mathrm{~cm})$, with a wall thickness of $0.090 \mathrm{in} .(2.30 \mathrm{~mm})$. Mounting stake bolts were galvanized steel. Pedestal hardware was of stainless steel material.

4. Painted galvanized steel channel type pedestal, green in color, 4-1/4 in. $\times 10-1 / 4$ in. $\times 41$ in. $(10.80 \mathrm{~cm} \times 26.0 \mathrm{~cm} \times$ $104.10 \mathrm{~cm}$ ), with a wall thickness of $0.075 \mathrm{in.}(1.90 \mathrm{~mm})$. Secured to a painted galvanized steel mounting stake, 1 in. $x$ 2 in. $x 42$ in. $(2.50 \mathrm{~cm} \times 5.10 \mathrm{~cm} \times 106.70 \mathrm{~cm})$, with a wall thickness of $0.090 \mathrm{in.}(2.30 \mathrm{~mm})$. Mounting stake bolts were galvanized steel. Pedestal hardware was of stainless steel material.

5. Fiberglass and polyvinylchioride (PVC) dome type pedestal. Fiberglass cover plate, green in color, 4-3/4 in. (12.10 cm) in diameter, 23 in. $(58.40 \mathrm{~cm})$ high, and a wall thickness of $0.20 \mathrm{in}$. ( $5.10 \mathrm{~mm}$ ). Secured to a polyvinylchloride (PVC) integrated back plate and mounting stake, $4-1 / 2$ in. $(11.40 \mathrm{~cm})$ in diameter, $54 \mathrm{in.}(137.20 \mathrm{~cm})$ high, and a wall thickness of 0.25 in. $(6.40 \mathrm{~mm})$. Mounting bolts (studs) were of an aluminum alloy. Pedestal hardware was of both stainless steel material and an aluminum alloy. 


\section{Table 1. (continued)}

\begin{tabular}{ll}
\hline System & \multicolumn{1}{c}{ Description } \\
\hline 6 & $\begin{array}{l}\text { This system was the same as System } 2 \text {, except that the pedestal } \\
\text { hardware had no plated steel materials. }\end{array}$ \\
$7 . \quad$ Painted galvanized steel mounting stake, 1 in. $\times 2$ in. $\times 42$ in. \\
$(2.50 \mathrm{~cm} \times 5.10 \mathrm{~cm} \times 106.70 \mathrm{~cm})$. This mounting stake was the \\
same type used in System 4.
\end{tabular}

Note: In Systems 1 through 6 an electrical connecting assembly was used which involves four parts of hardware that are referred to in this report as electrical connector, connector to bracket securing hardware, bracket, and bracket to back plate hardware. The hardware part listed as the "bracket" will be referred to as the insulated supporting strap in System 5 . Various types of materials were used in the electrical connecting assembly including stainless steel, plated steel, and aluminum alloys. 


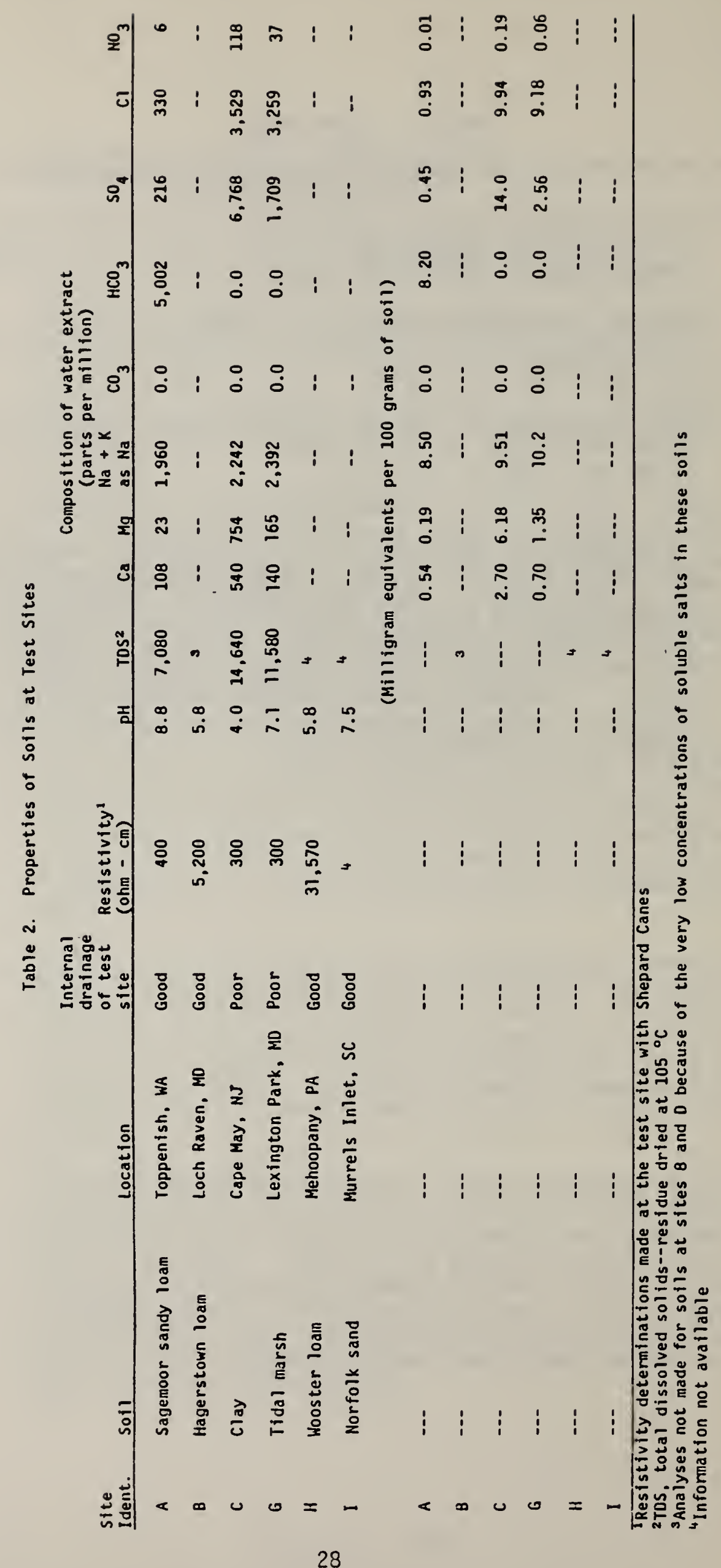


Table 3. Rating Code for the Performance Evaluation of Telephone Cable Pedestals.

\begin{tabular}{|c|c|c|}
\hline Rating & Performance & Degree of Corrosion \\
\hline 10 & Excellent & $\begin{array}{l}\text { Uneffected. No indication of corrosion or } \\
\text { degradation of fiberglass surfaces. }\end{array}$ \\
\hline 9 & Excellent & $\begin{array}{l}\text { Superficial rust, etching and/or pitting. } \\
\text { Superficial dissipation of galvanized and/or } \\
\text { plated steel surfaces. }\end{array}$ \\
\hline 8 & Very Good & $\begin{array}{l}\text { Uniform metal attack, rust, and/or slight } \\
\text { pitting. Slight dissipation of galvanized } \\
\text { and/or plated steel surfaces. Blistering of } \\
\text { paint on galvanized steel surfaces. Very } \\
\text { slight degradation (fiberglass fibers slightly } \\
\text { separating from resin). Color of pedestal } \\
\text { and/or warning sign slightly lighter than that } \\
\text { of original. }\end{array}$ \\
\hline 7 & Good & $\begin{array}{l}\text { Galvanized steel surfaces exposed after blis- } \\
\text { tering and/or undercutting of paint, with slight } \\
\text { dissipation of galvanized steel surface. Pitting } \\
\text { of } 0.001 \text { in. or less on hardware metal surfaces. } \\
\text { Slight degradation of fiberglass surfaces } \\
\text { (fiberglass fibers separating from resin but } \\
\text { still are embedded in resin). }\end{array}$ \\
\hline 6 & Good & $\begin{array}{l}\text { Dissipation of galvanized steel surfaces with } \\
\text { rust areas showing on galvanized and/or plated } \\
\text { steel surfaces from } 1 \text { to } 10 \text { percent. Color of } \\
\text { pedestal and/or warning sign moderately lighter } \\
\text { than that of original. }\end{array}$ \\
\hline 5 & Fair & $\begin{array}{l}\text { Moderate dissipation of galvanized steel } \\
\text { surfaces with rust areas occurring on } \\
\text { galvanized and/or plated steel surfaces } \\
\text { from } 10 \text { to } 25 \text { percent. Localized pitting on } \\
\text { the above rust areas and other metal surfaces } \\
0.001 \text { in. to } 0.005 \text { in. Moderate degradation } \\
\text { of the fiberglass surfaces (glass fibers } \\
\text { cannot be mechanically lifted from resin). }\end{array}$ \\
\hline 4 & Poor & $\begin{array}{l}\text { Dissipation of galvanized and/or plated steel } \\
\text { surfaces with rust areas occuring over } 25 \text { to } \\
50 \text { percent of surface. Pitting on metal surfaces } \\
0.005 \text { in. to } 0.010 \text { in. Degradation of the } \\
\text { fiberglass (glass fibers can be mechanically } \\
\text { lifted from resin). Color of pedestal and/or } \\
\text { warning sign semi-glossy and considerably lighter } \\
\text { than original. }\end{array}$ \\
\hline
\end{tabular}


Table 3 (continued)

\begin{tabular}{|c|c|c|}
\hline Rating & Performance & Degree of Corrosion \\
\hline 3 & Poor & $\begin{array}{l}\text { Dissipation of galvanized and/or plated steel } \\
\text { surfaces with rust areas occurring over } 50 \text { to } \\
75 \text { percent of surface. Pitting on the above } \\
\text { rust areas and other metal surfaces. } 0.010 \text { in. } \\
\text { to } 0.020 \text { in. Severe degradation of the fiber- } \\
\text { glass surfaces (glass fiber standing out from } \\
\text { resin). }\end{array}$ \\
\hline 2 & Poor & $\begin{array}{l}\text { Galvanized and/or plated steel surfaces dissi- } \\
\text { pated } 100 \text { percent. Pitting on metal surfaces } \\
0.020 \text { in. to } 0.030 \text { in. Severe degradation of } \\
\text { fiberglass surfaces with fibers standing out } \\
\text { severely. Warning sign separating from pedestal. } \\
\text { Color of pedestal and/or warning sign not } \\
\text { glossy and considerably lighter than original. }\end{array}$ \\
\hline 1 & Very Poor & $\begin{array}{l}\text { Severe Corrosion: Pitting on metal surface } \\
\text { over } 0.030 \text { in. Severe degradation of fiberglass } \\
\text { surfaces with delamination. }\end{array}$ \\
\hline 0 & Very Poor & $\begin{array}{l}\text { Severe Corrosion: Metal surfaces perforated by } \\
\text { corrosion. Fiberglass has delaminated or } \\
\text { cracked, permitting dust and sunlight inside } \\
\text { pedestal. Warning sign has completely separated } \\
\text { from pedestal. Metal attack and/or fading has } \\
\text { made warning sign not legible. Color of } \\
\text { pedestal not glossy and is gray in color. }\end{array}$ \\
\hline
\end{tabular}


it

$\therefore \quad \therefore \quad \therefore$

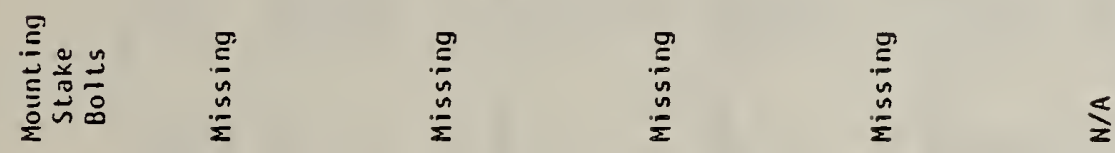

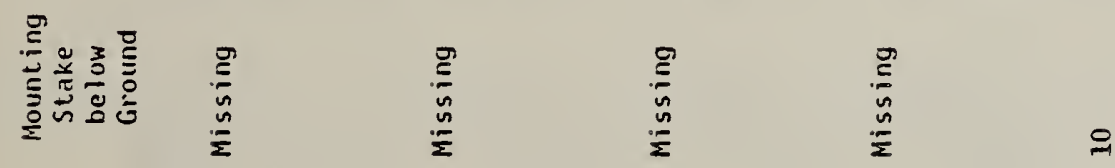

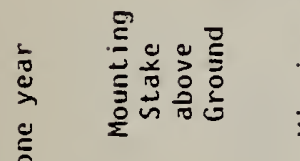

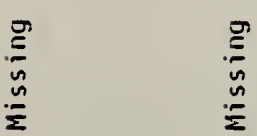

$\stackrel{\mathscr{Z}}{\frac{\mathscr{n}}{2}}$

욱

ప

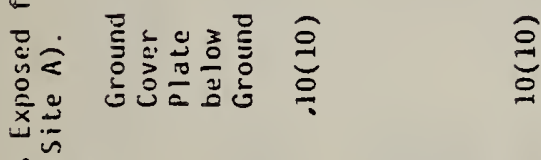

$\stackrel{\varrho}{\stackrel{0}{0}}$

$\stackrel{\varrho}{\Xi}$

$\frac{s}{z}$

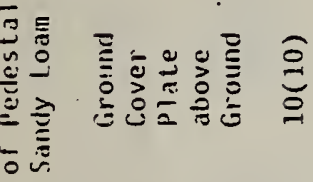

$\widehat{\varrho} \quad \stackrel{\varrho}{\Xi} \quad \widehat{\Xi}$

$\stackrel{\varrho}{\vdots} \quad \vdots$

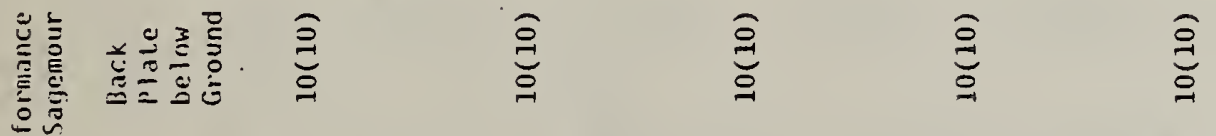

$\stackrel{\bar{c}}{c} \equiv$

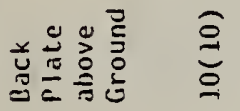

ఏ્త

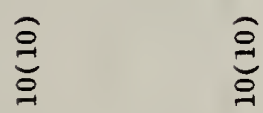

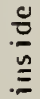

$\frac{\frac{1}{\pi}}{\frac{\pi}{a}}$

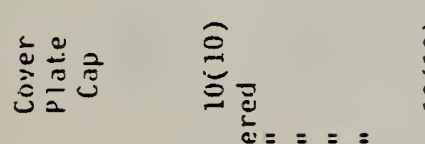

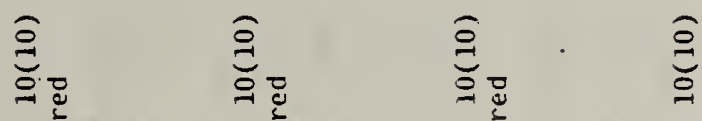

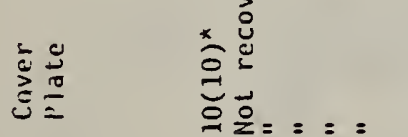

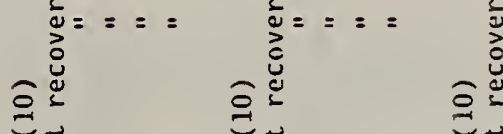

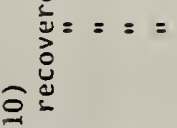

t)
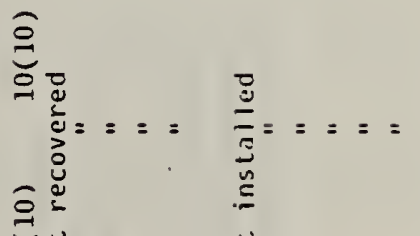

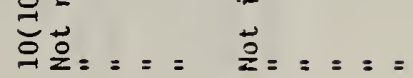

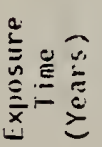

$\because \sim m \leftarrow \ln$

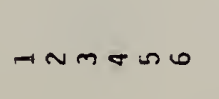

$\frac{E}{\grave{n}}$

$\sim$

m

$-\sim m<\infty e$

$\rightarrow N m=n \infty$

$-n m<n o$

$-n m=\Omega 0$

$\sigma$

$n$

๑ 


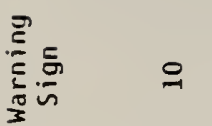

요요

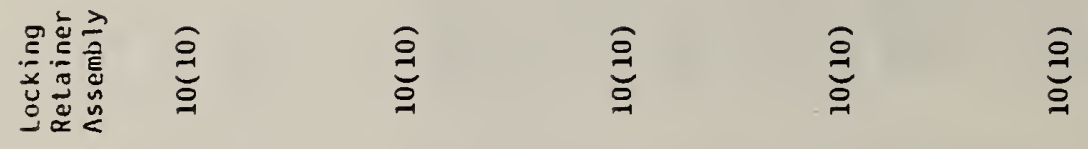

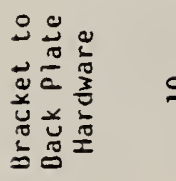

의

$9 \quad 9$

운

욱

离

$£$

운

웅

욱

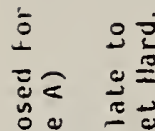

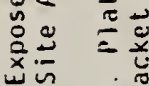

9

우

운

옹

욱

苛言

施

产

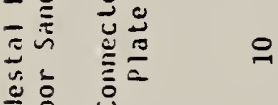

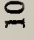

$\cong$

옹

운

$=\bar{m}$

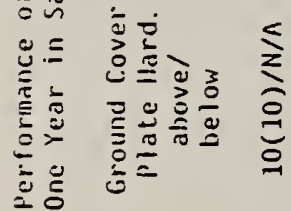

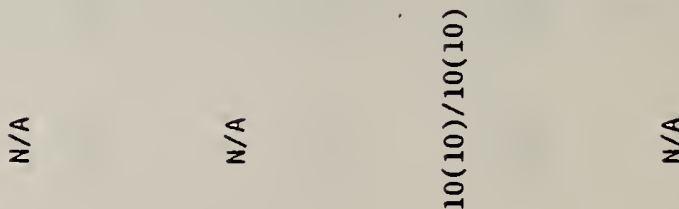

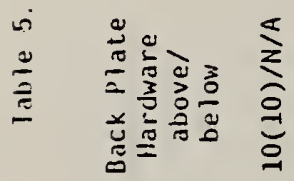

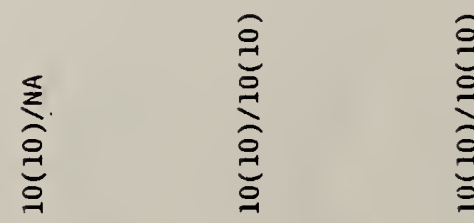

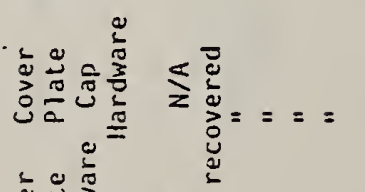

要离

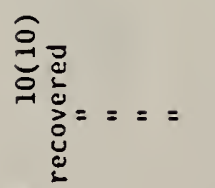

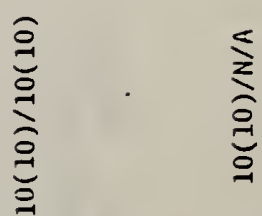

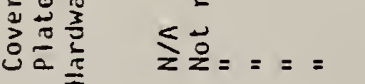
造<smiles></smiles>

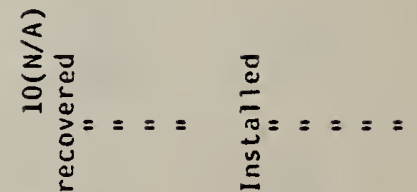

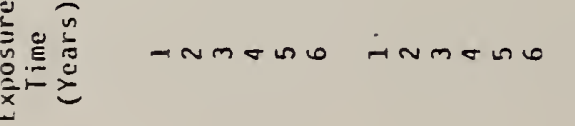

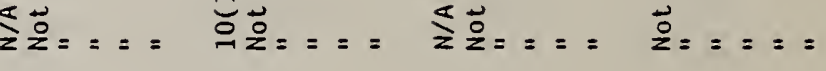

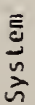


露

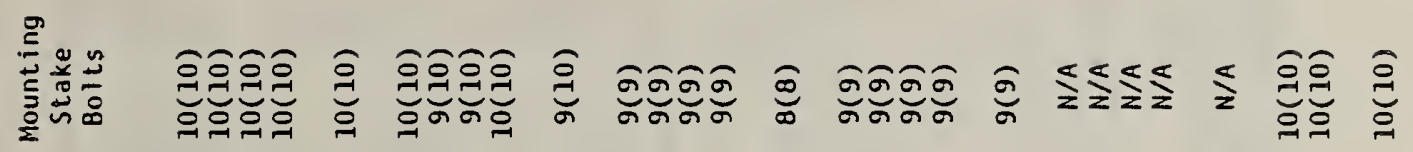
Imp!n

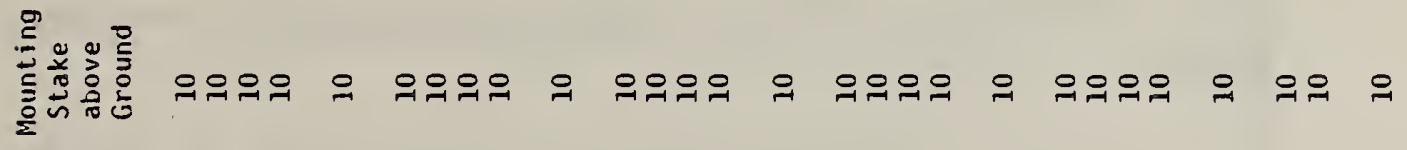
:

$\sqrt{3}$

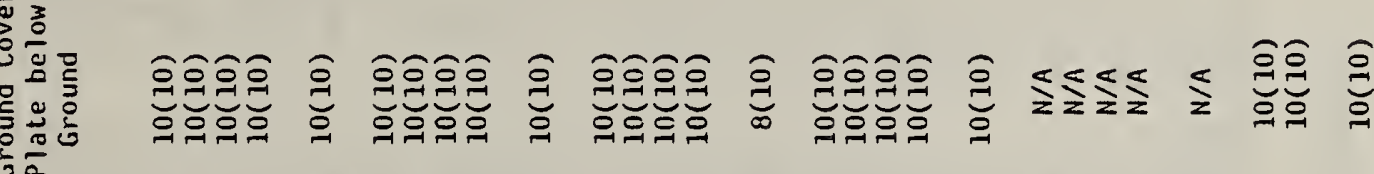
$\frac{6}{2}$

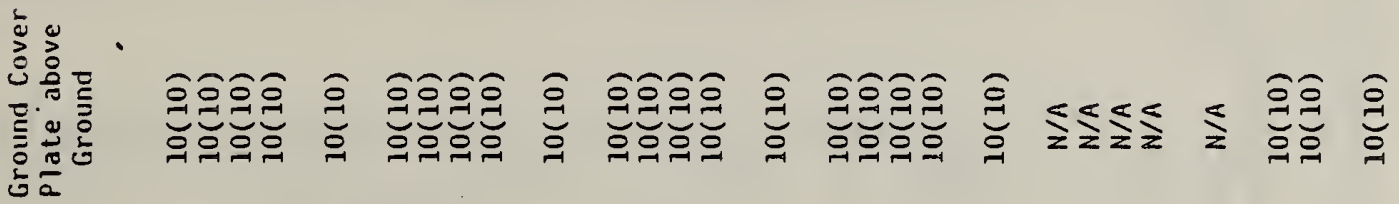
ن. 范范

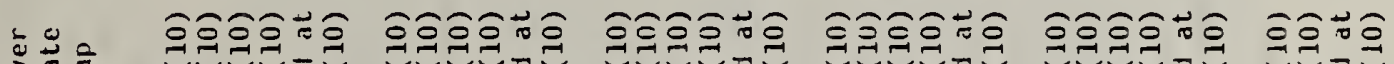
过热 矛

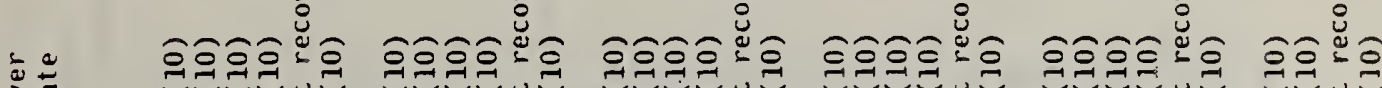

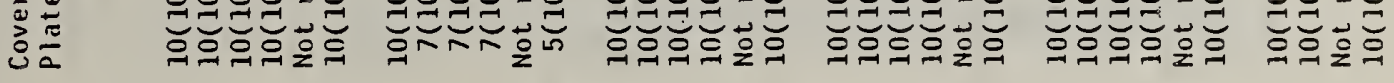

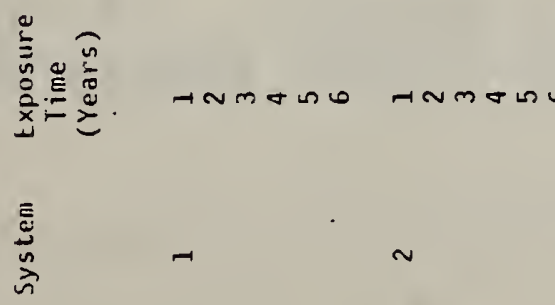




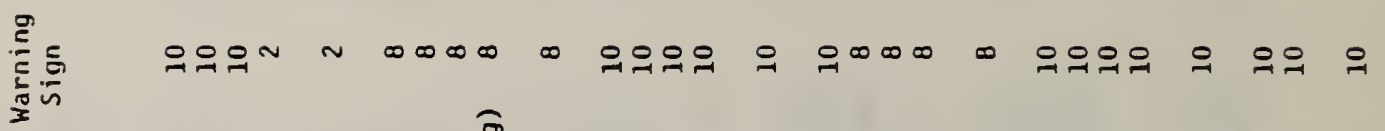

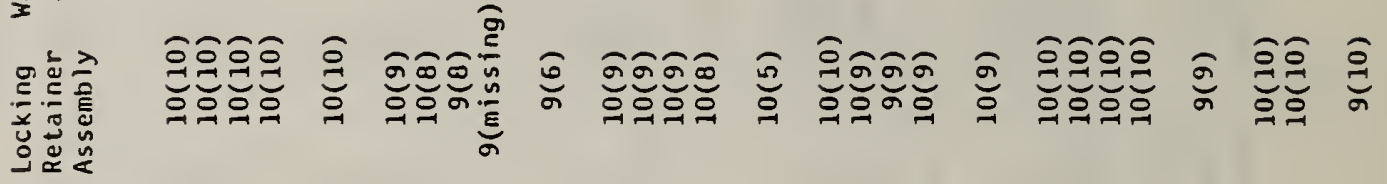

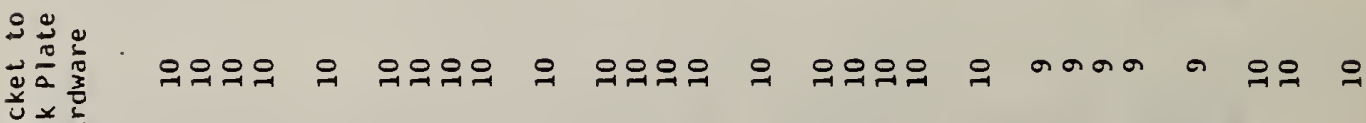
䇏高

0

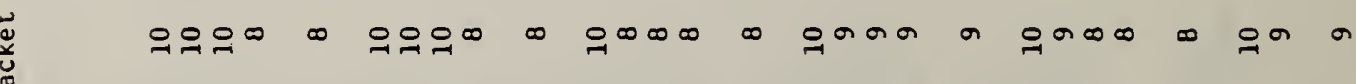

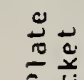
$-2 \frac{1}{2}$

으은드

a 응으음 a

orana a

응으유

क्ष $\left(\frac{100}{20}\right.$ 过

焉

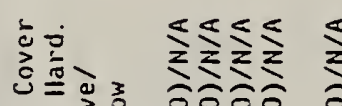

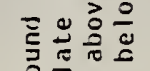

응으응

융응유응음

응

응융 $\infty$ 유요

$\infty \infty$

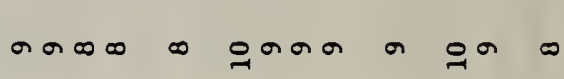

프

$\frac{1}{5}=$

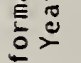

$\pm \frac{x}{4}$

$\frac{a}{\pi}$

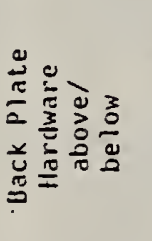

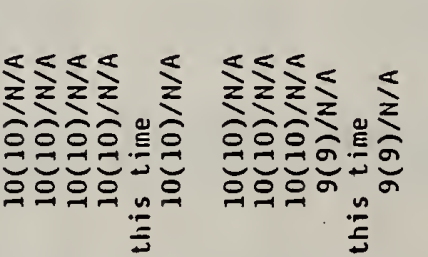

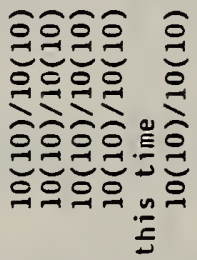

ิํํำ

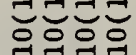

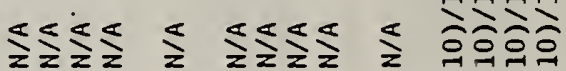

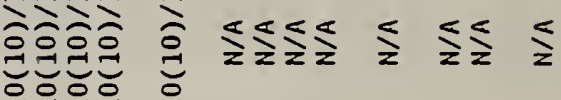

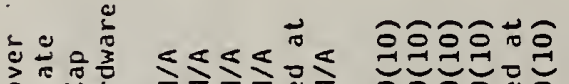

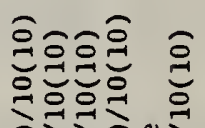

ิิ

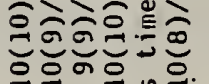

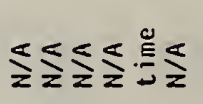

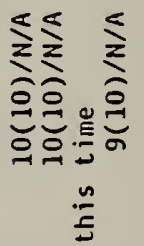

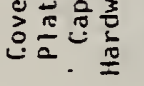

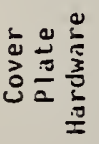

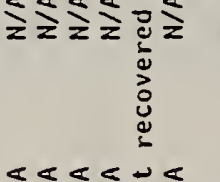

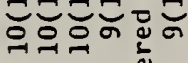

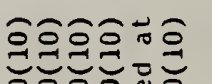

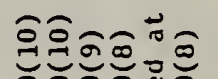

$\frac{n}{5}$

อิอิธอ

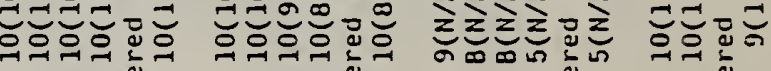

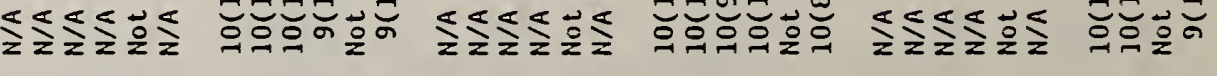
离望 


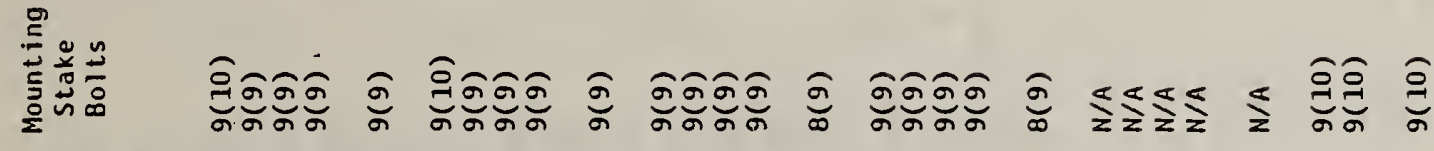

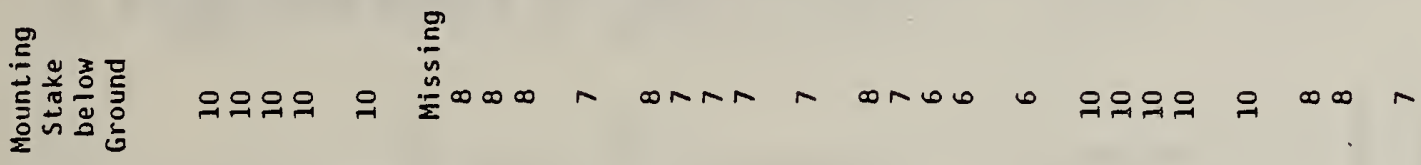

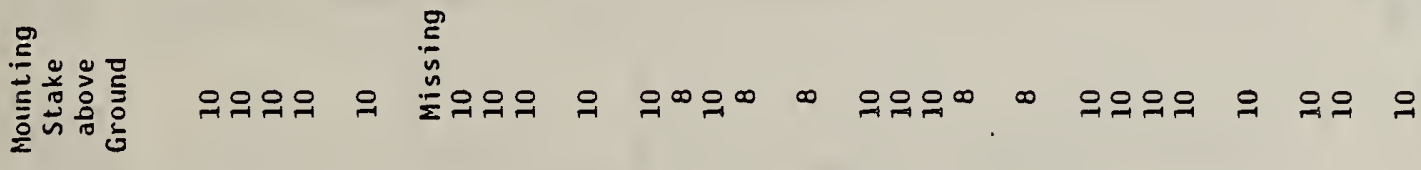

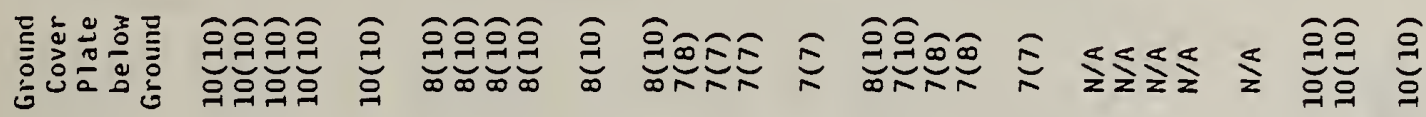

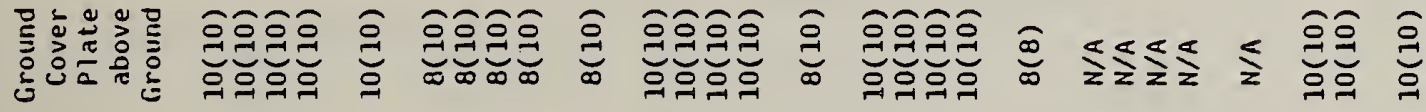

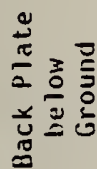

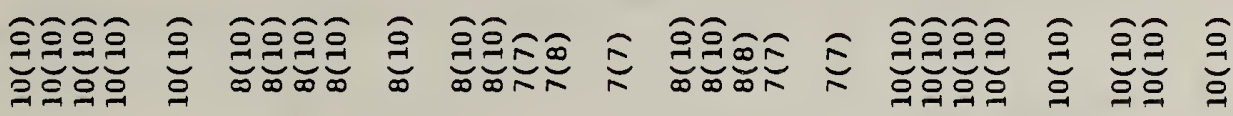
$\frac{5}{0}$

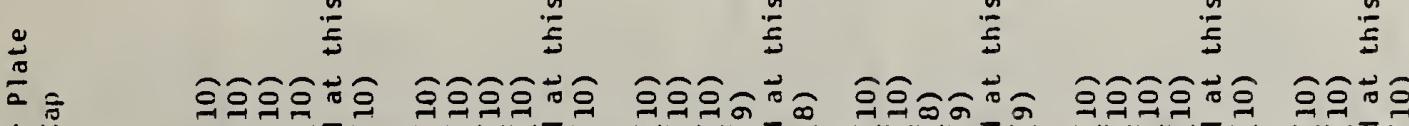

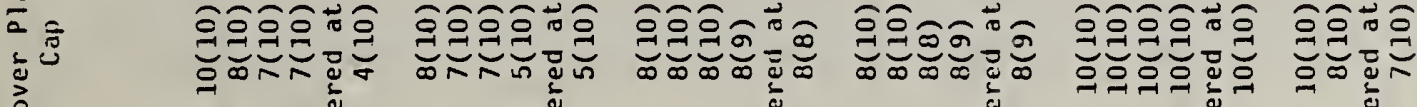

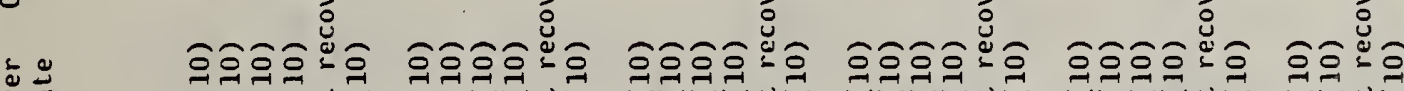

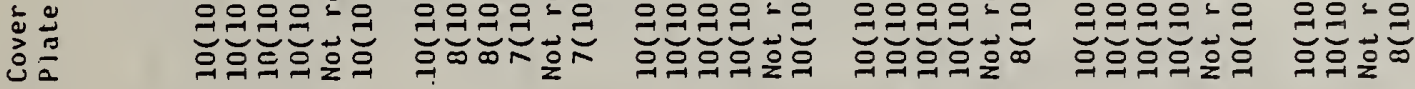

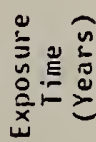

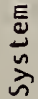
$\sim$ $m$ 


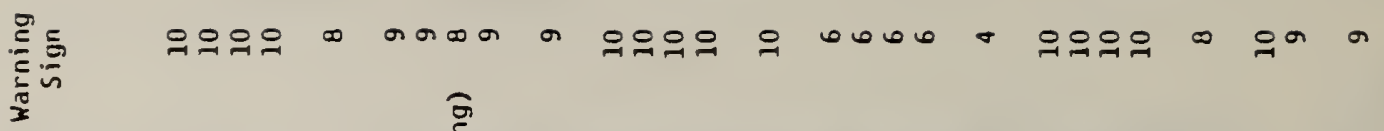

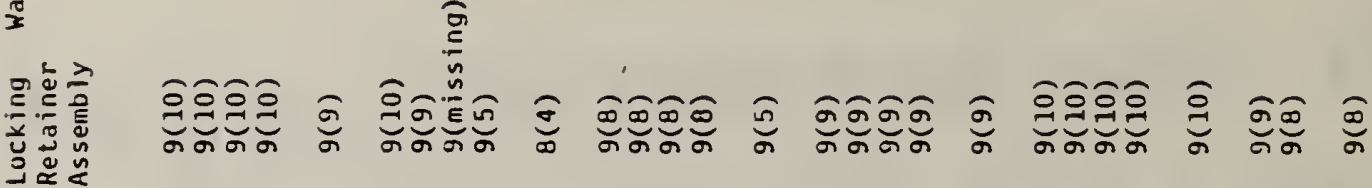

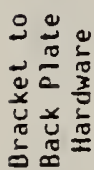

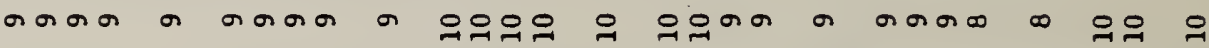

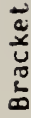

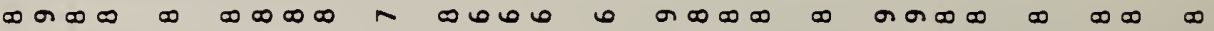

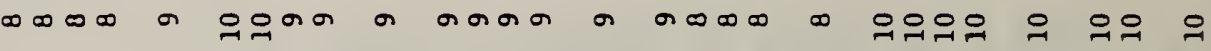

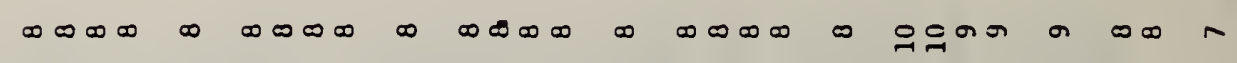

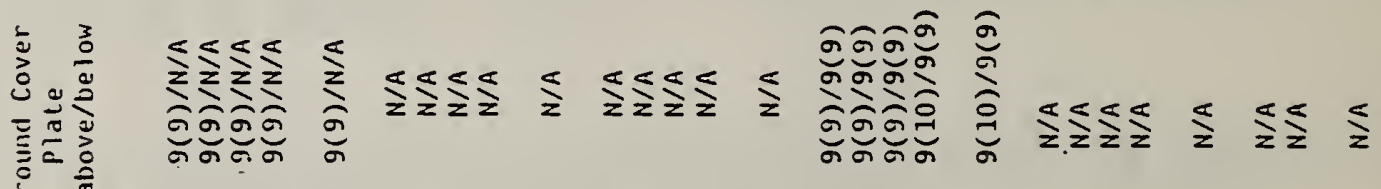

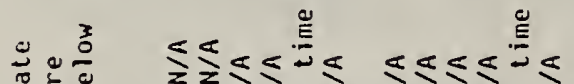

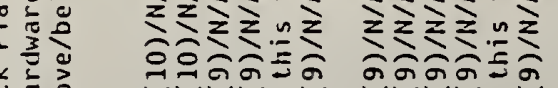

\section{อิ으}

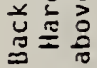

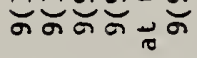

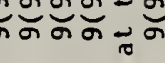

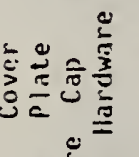

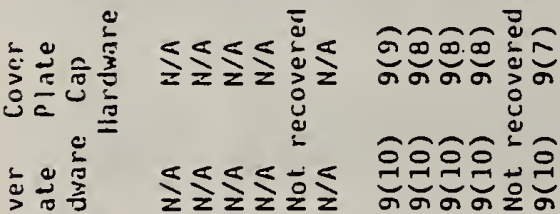

ษสํำ

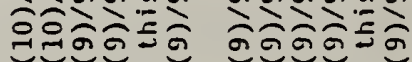

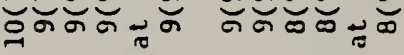

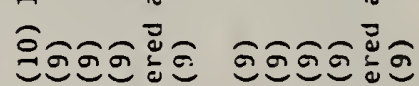

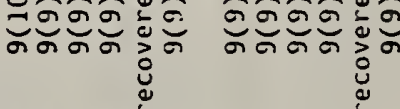

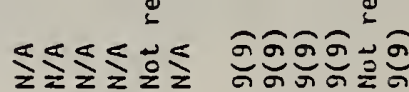

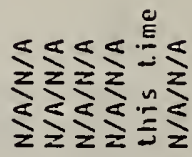

म

Ł£. $\sum$ 综 ล̆ล̆ $\frac{\pi}{2}$

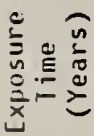

$-N m+n \in$

- $\rightarrow m \in n \in$

$\operatorname{tam} \theta \cos$

$\operatorname{~rnmo~}$

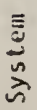




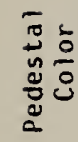

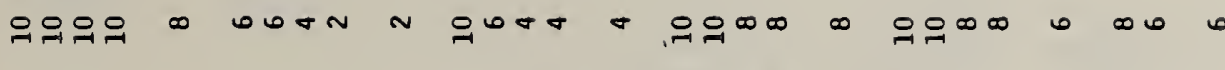

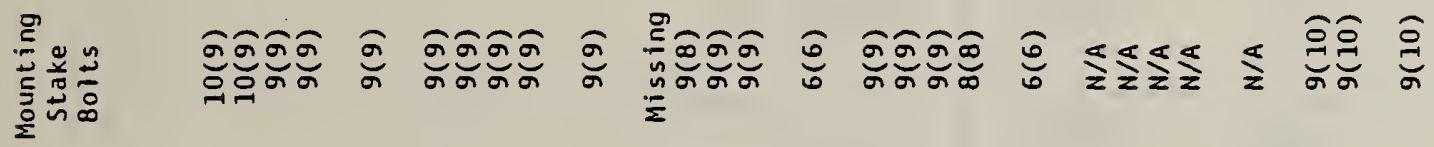

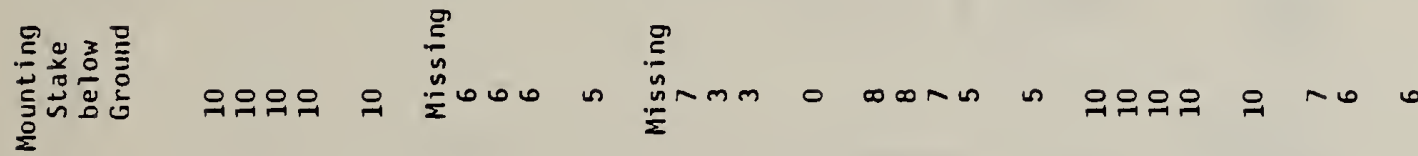

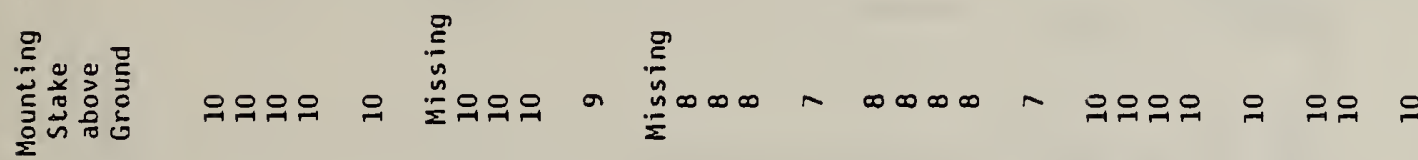
政

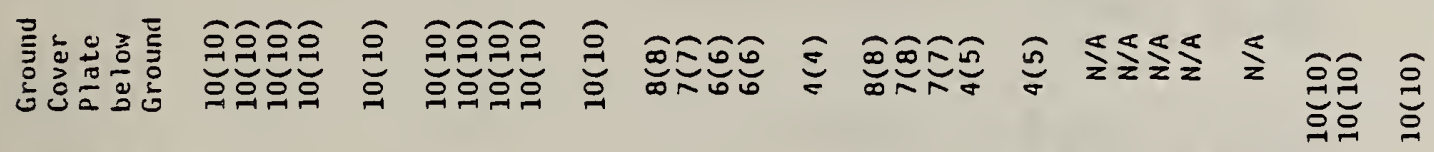

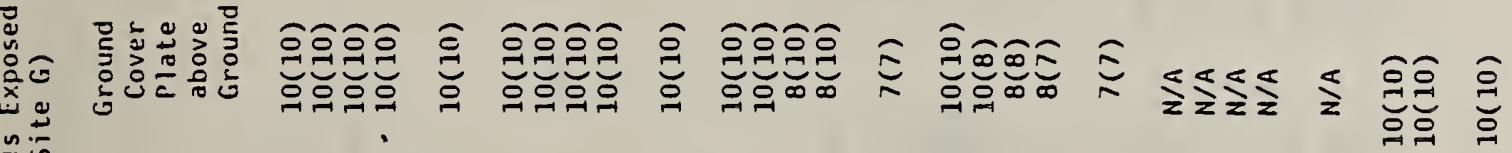

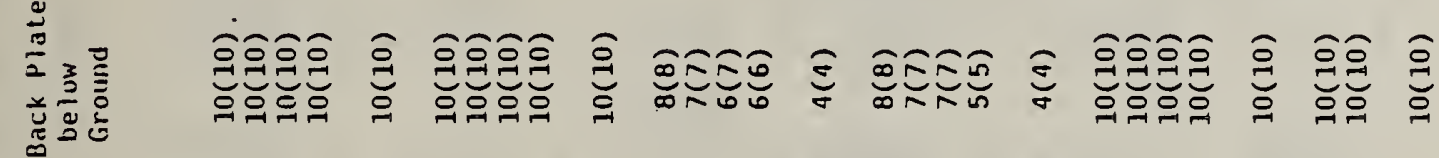
$\stackrel{0}{:}$

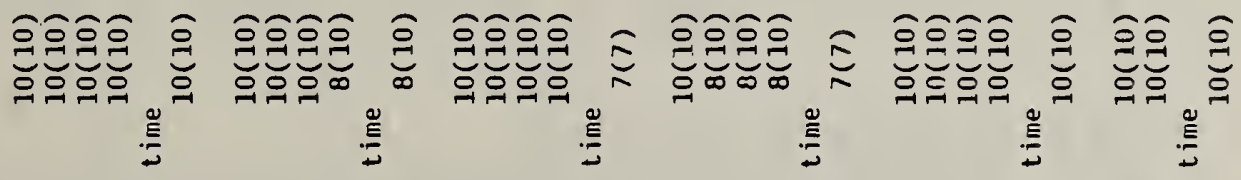

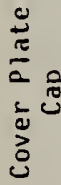

$\frac{0}{0}$

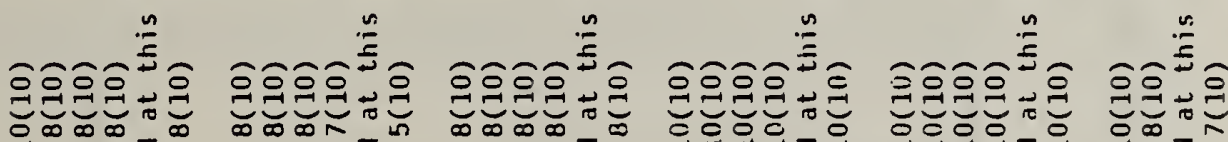

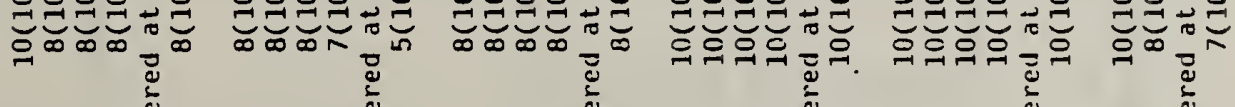

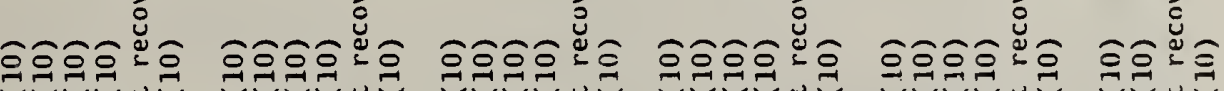

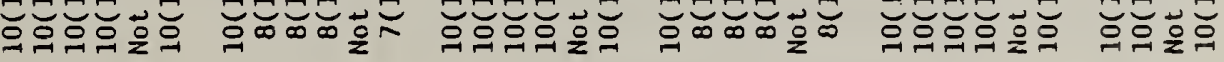

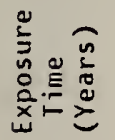

$\stackrel{\bar{E}}{\stackrel{E}{n}}$
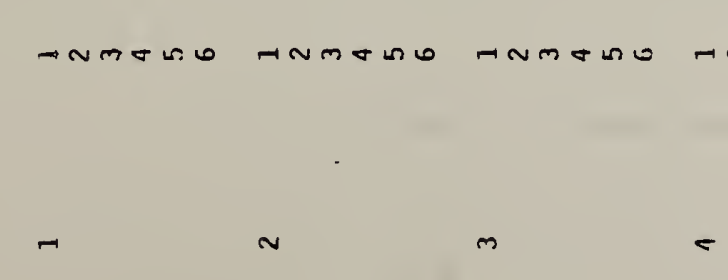


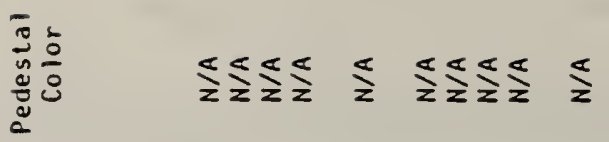

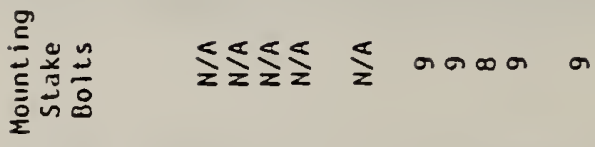

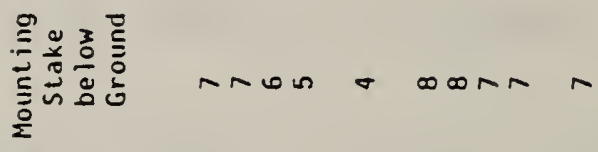

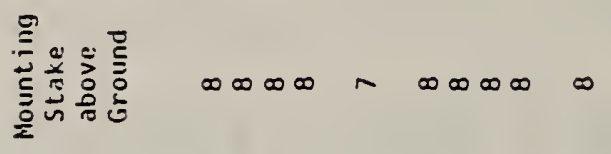

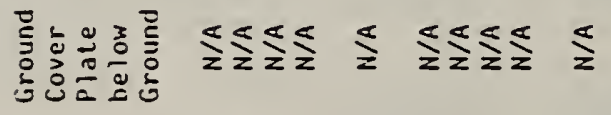

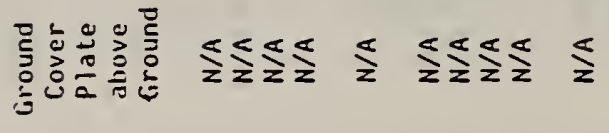

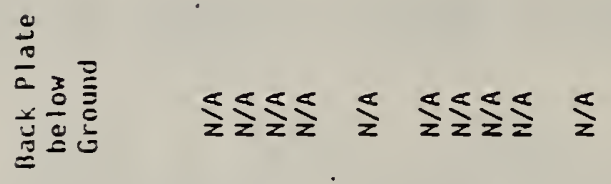

$\left.\frac{5}{0}\right)_{0}^{0}$

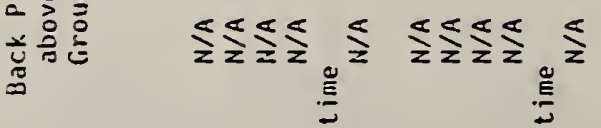

$\frac{0}{2}$
$\frac{1}{2}$
$\frac{1}{3}$

$\frac{0}{0}$

$\dddot{\infty}$

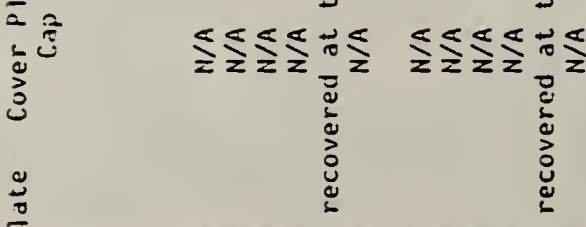

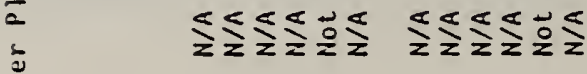

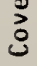

集 
高兽

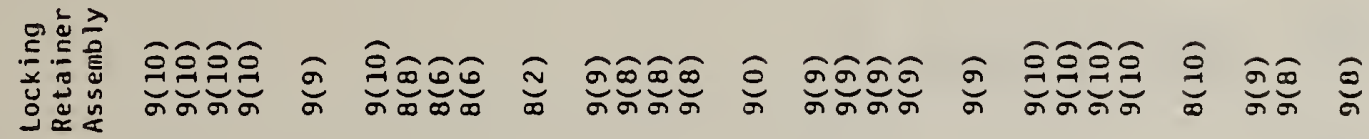

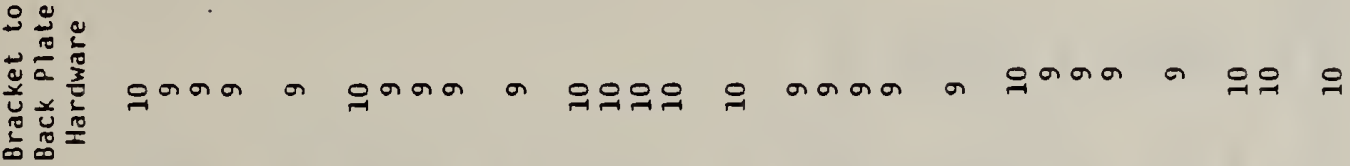

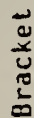

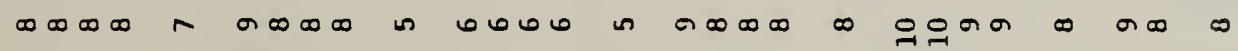

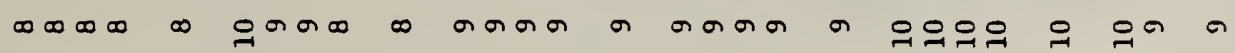
$\stackrel{\circ}{\stackrel{4}{0}}$

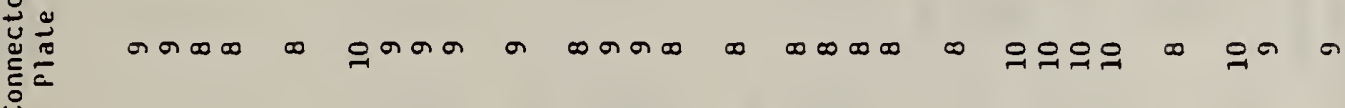

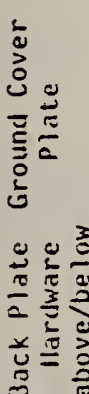

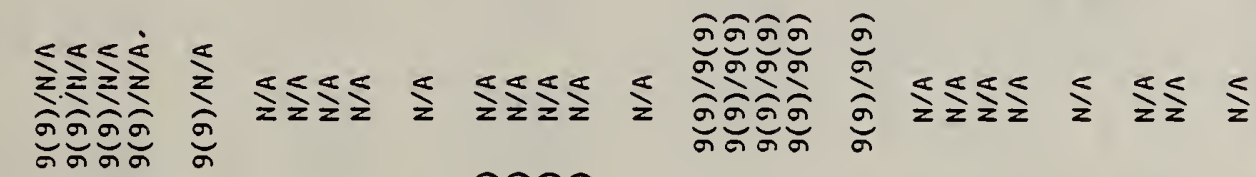

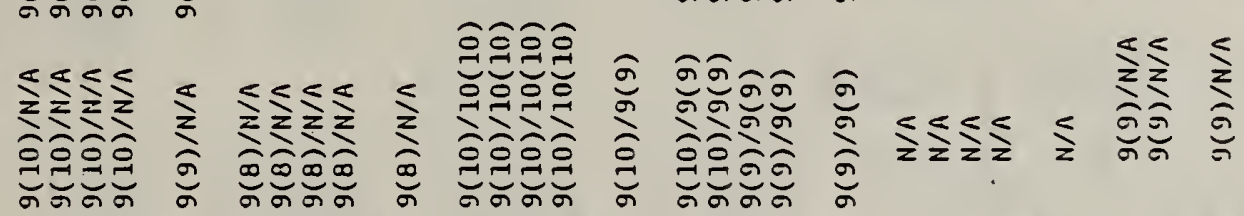
$=$ $\frac{2}{2}$

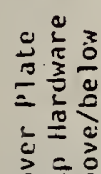

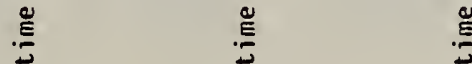<smiles>[CH][CH]</smiles><smiles>[CH][CH][CH]</smiles> 


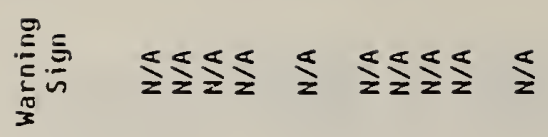

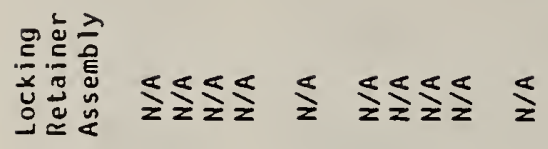

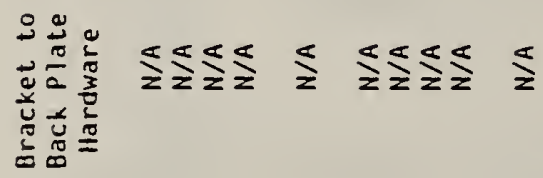

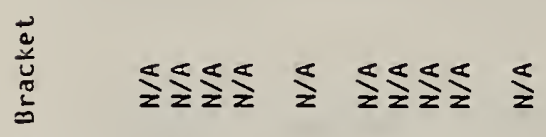

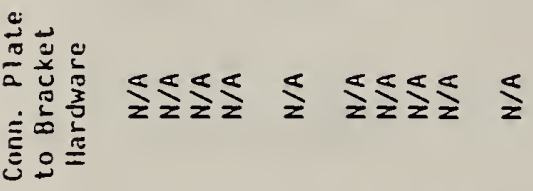

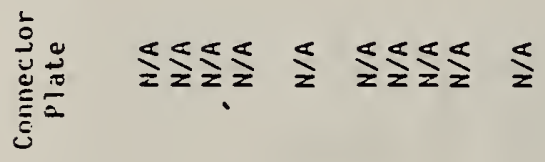
率。

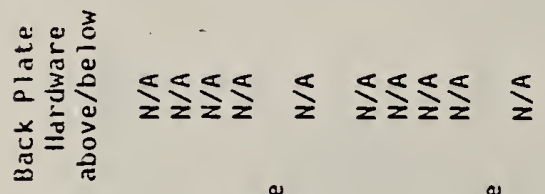

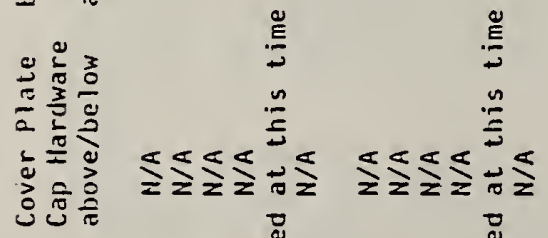

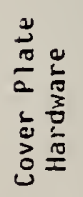

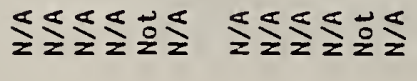

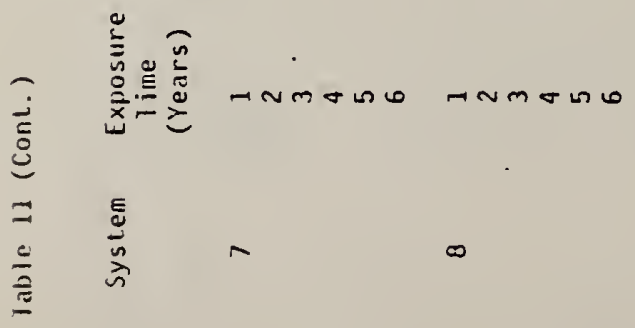


$\stackrel{\pi}{\stackrel{\pi}{u}}$

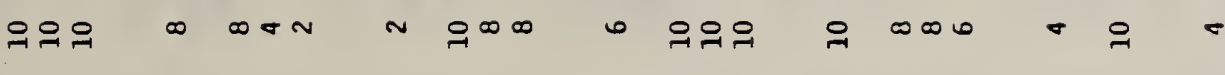

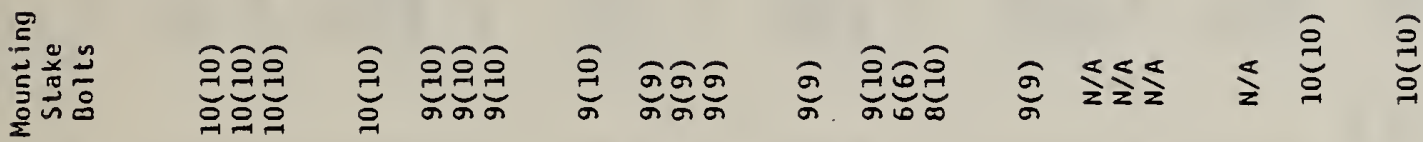

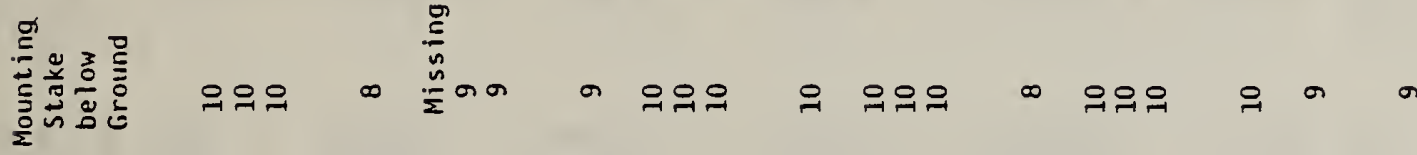

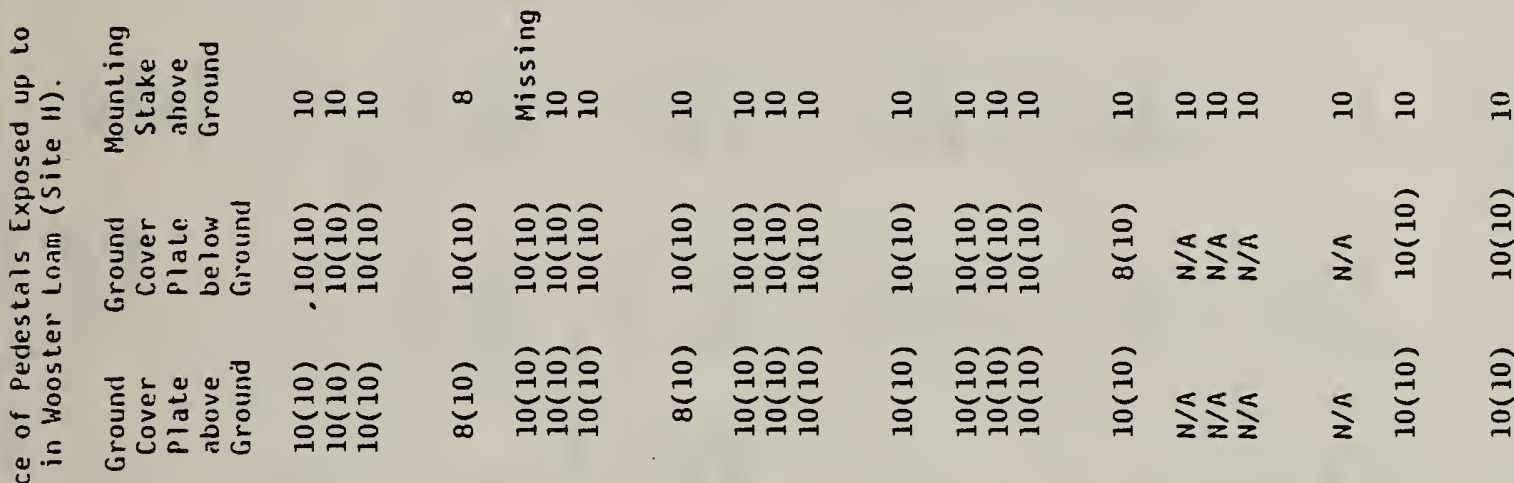

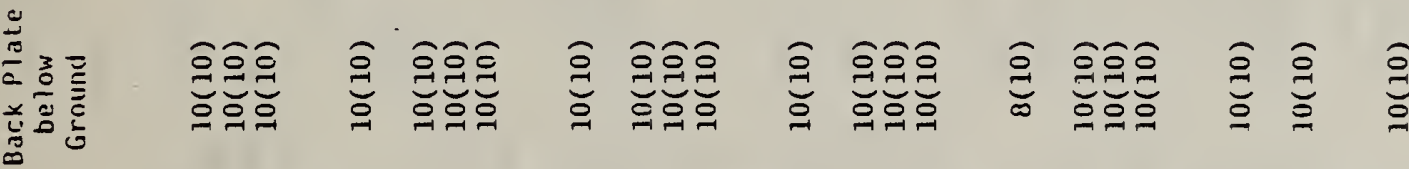

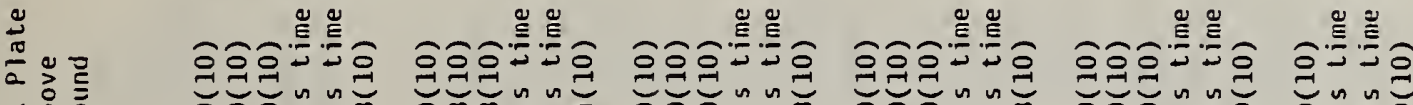

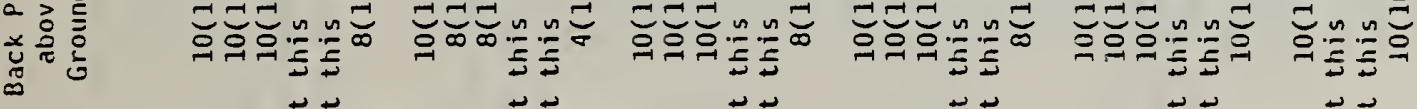

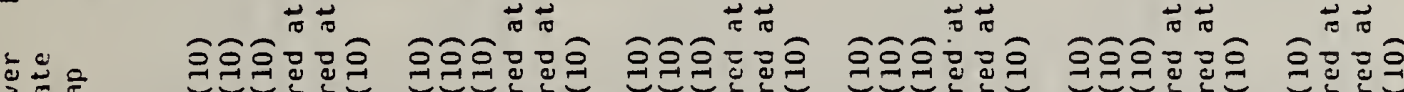

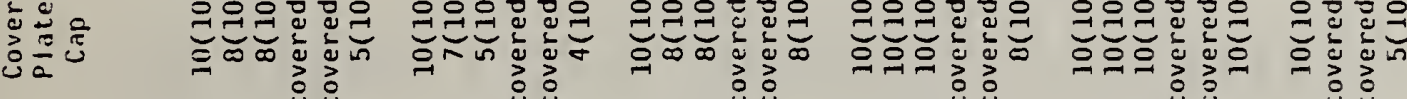

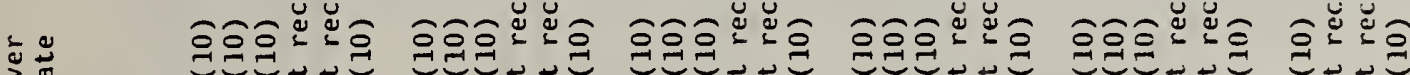

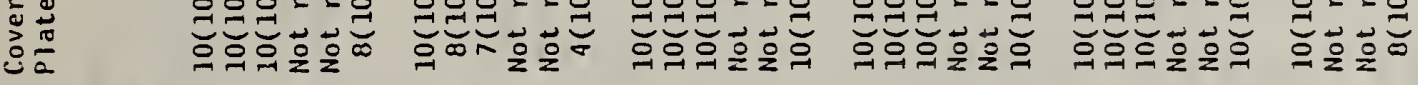

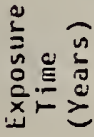

竎

m

$n$ 


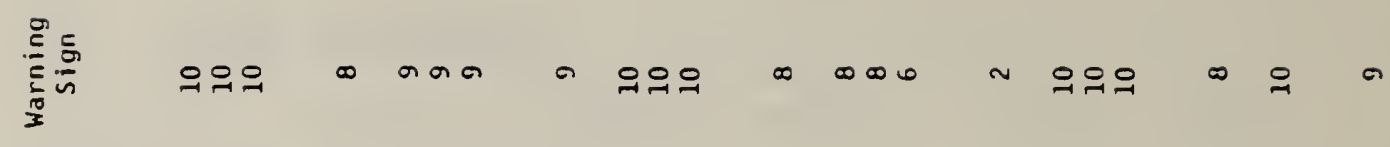

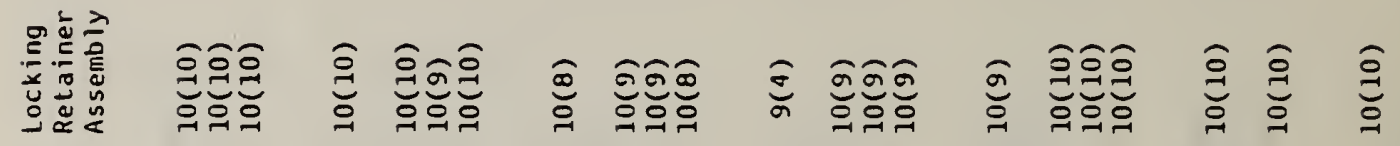

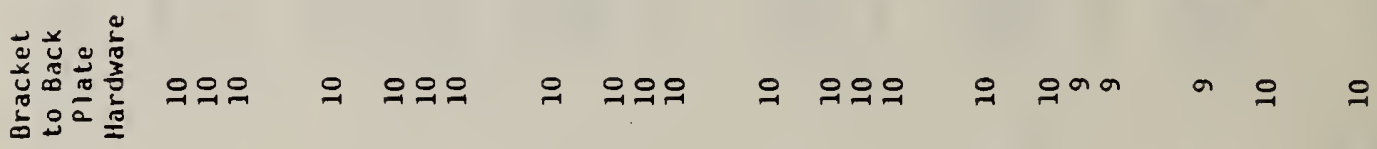
Don

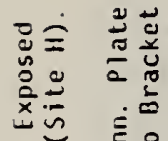

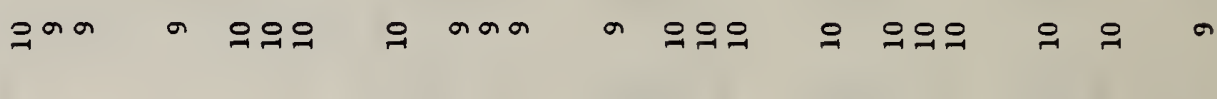

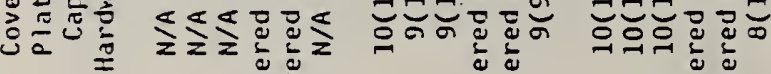

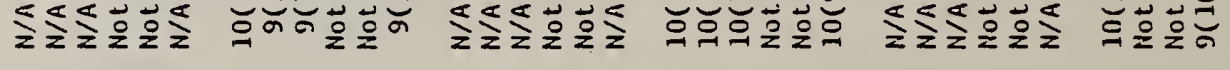

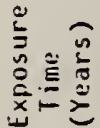

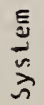




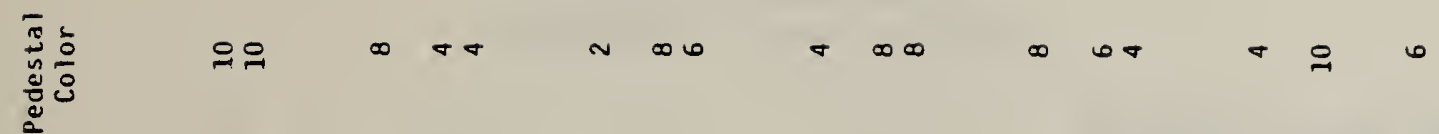

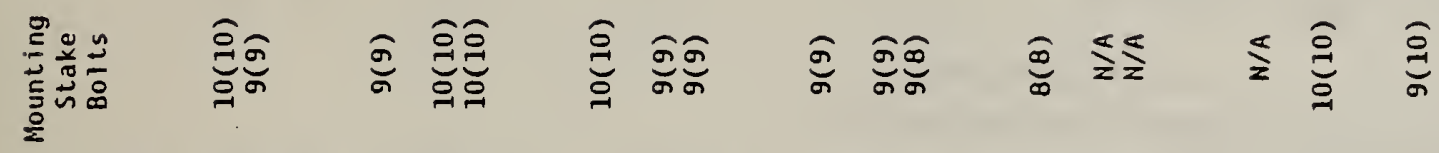

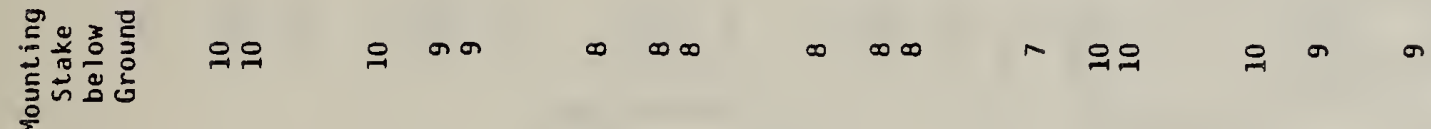

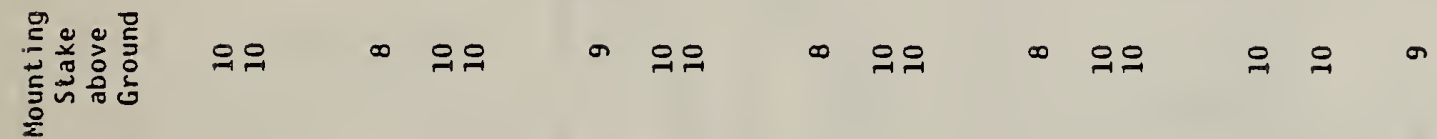

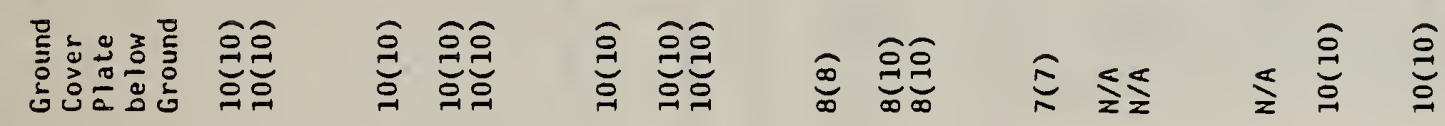

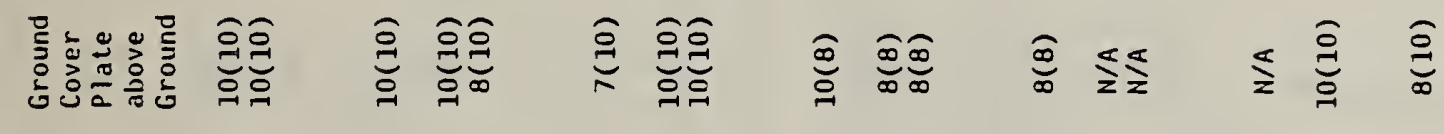

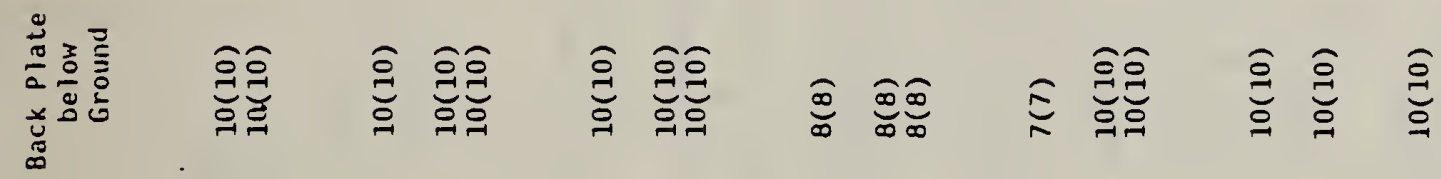

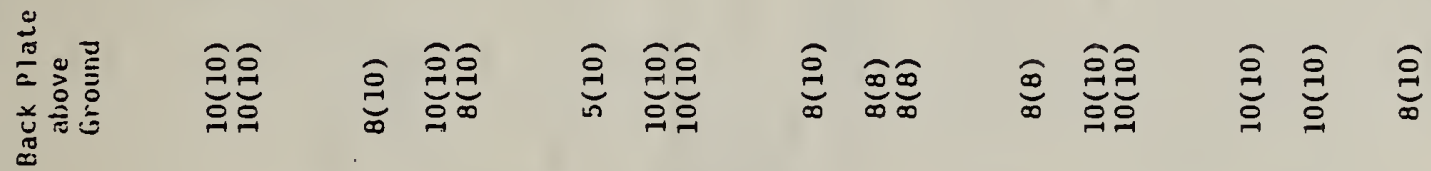

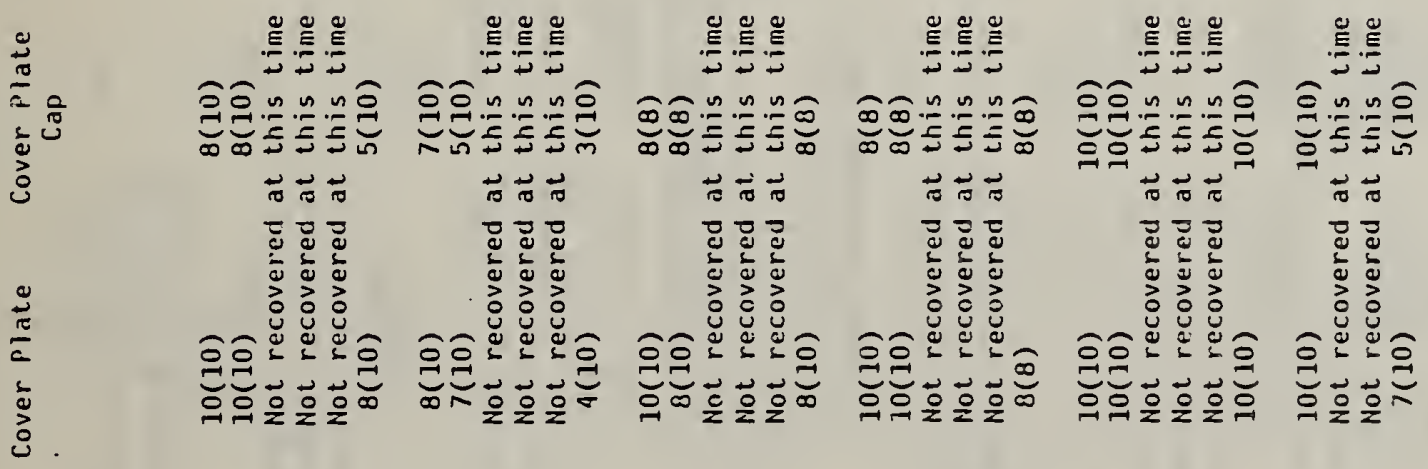

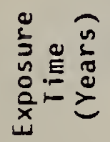
$\stackrel{\Xi}{\stackrel{\xi}{n}}$ $\sim$ 


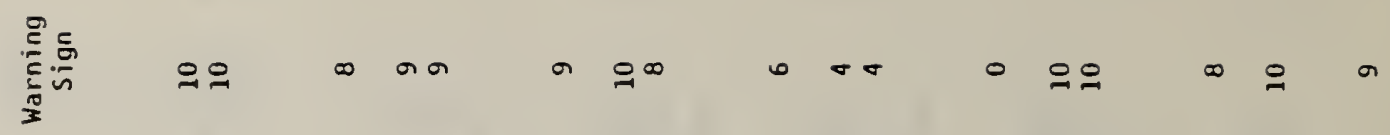

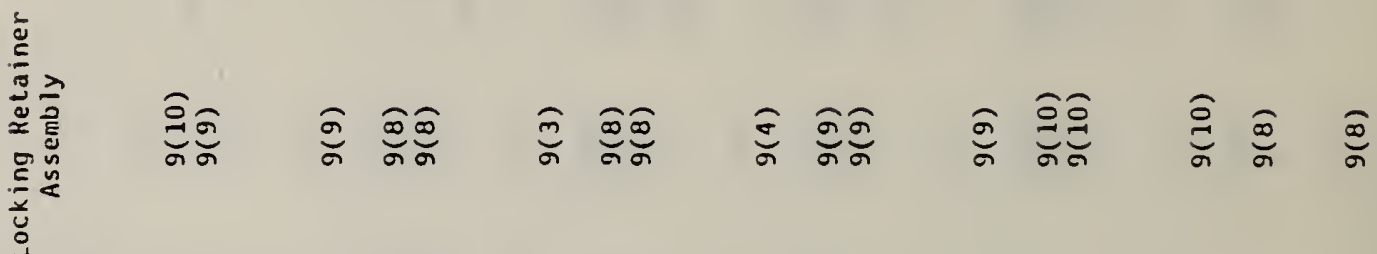
ar a 을

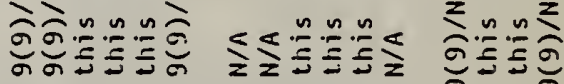

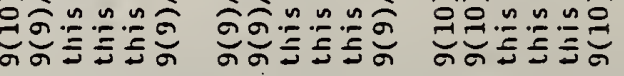

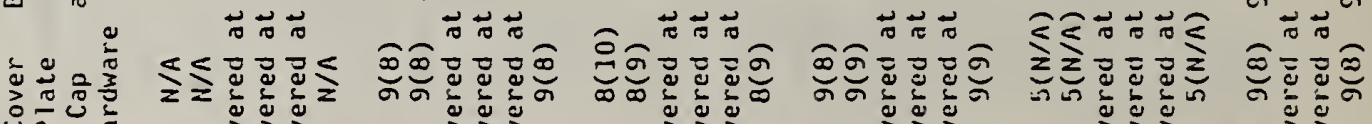

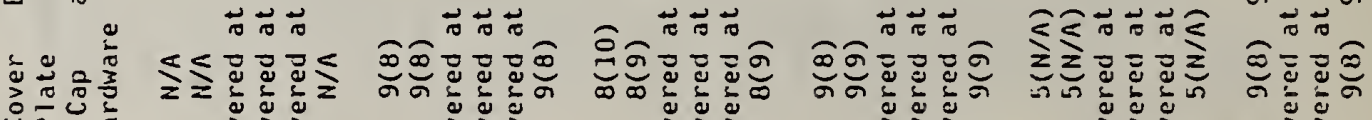

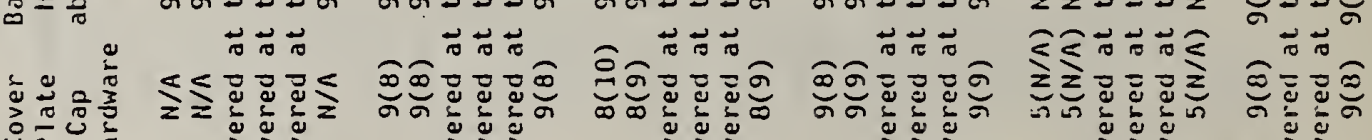

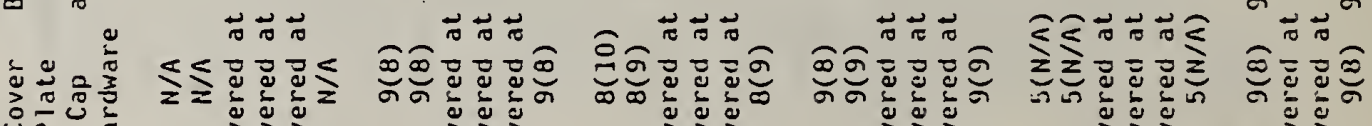

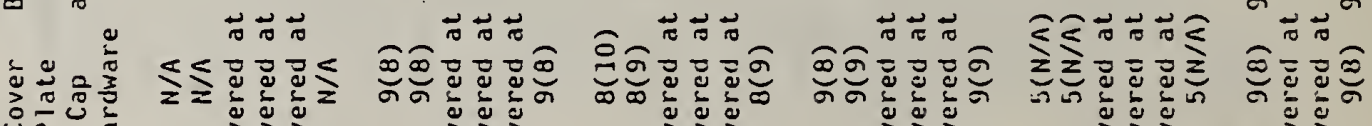

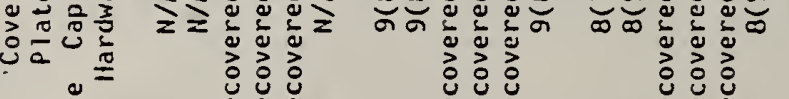


SYSTEMS $1,2,3,4$, and 6

CHANNEL TYPE PEDESTALS

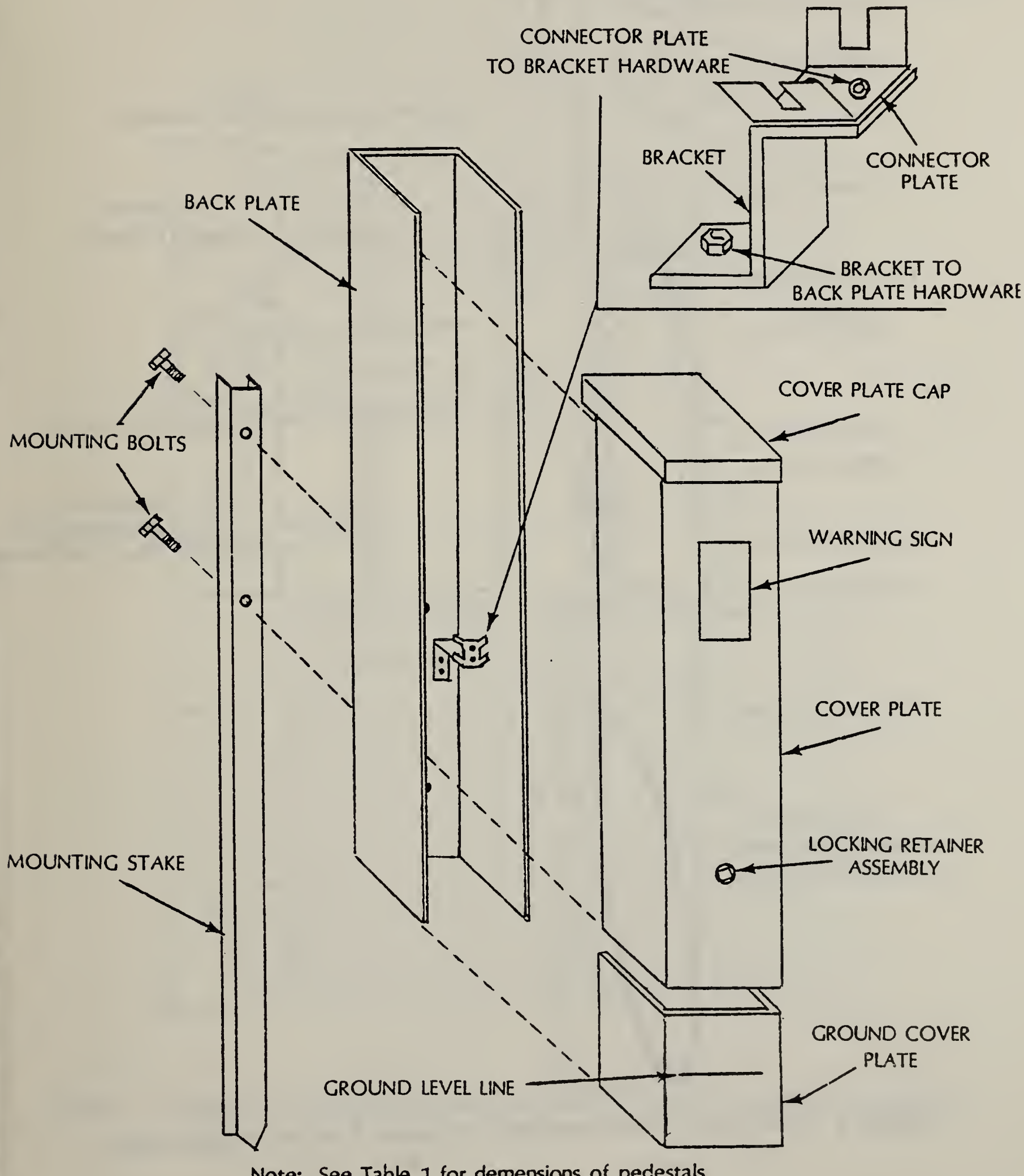

Note: See Table 1 for demensions of pedestals.

Figure 1 Various parts of pedestals for Systems $1,2,3,4$, and 6 before exposure test. 


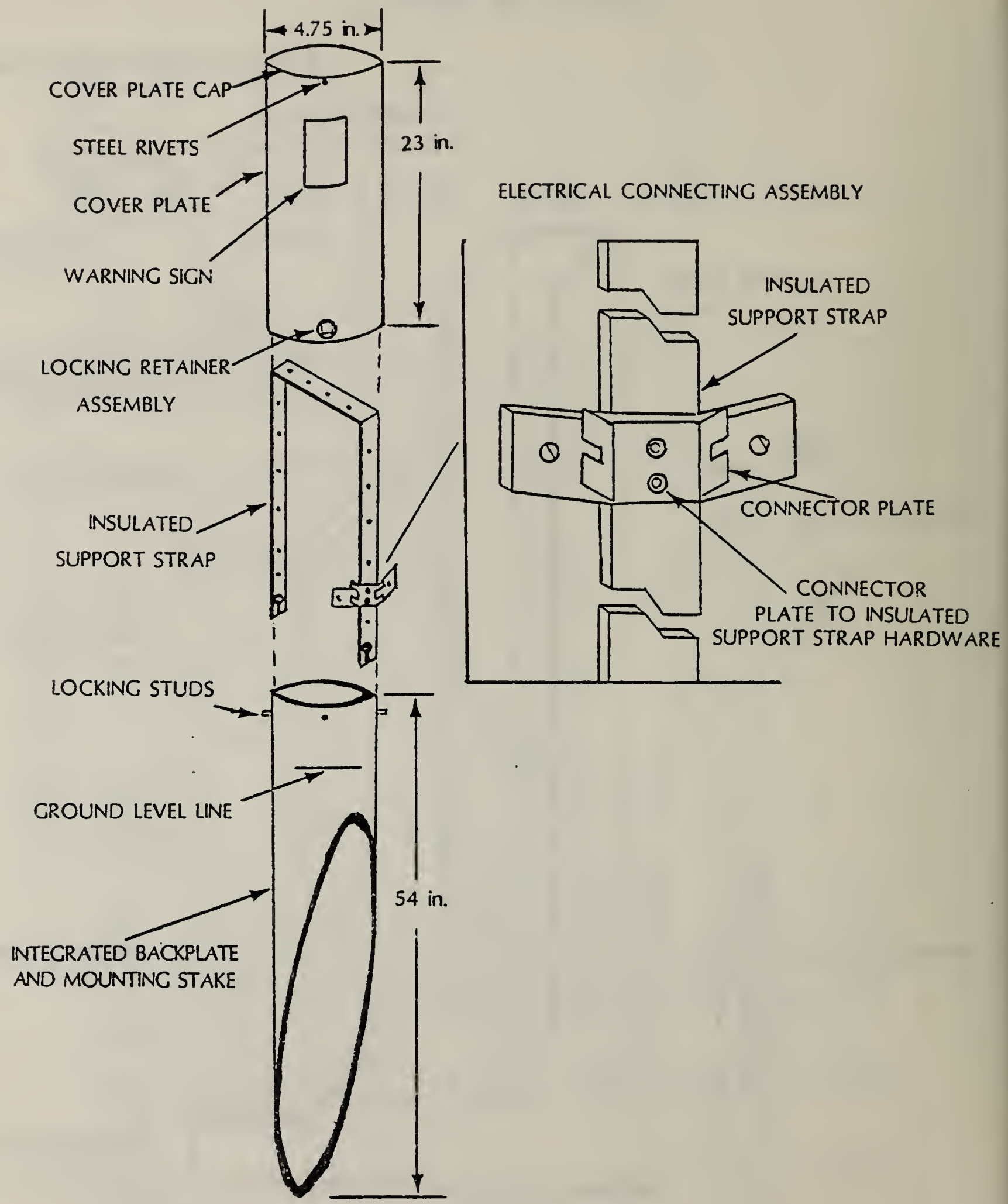

Figure 2 Various parts of the pedestal for System 5 before exposure test. 
SYSTEMS 7 and 8

MOUNTING STAKES

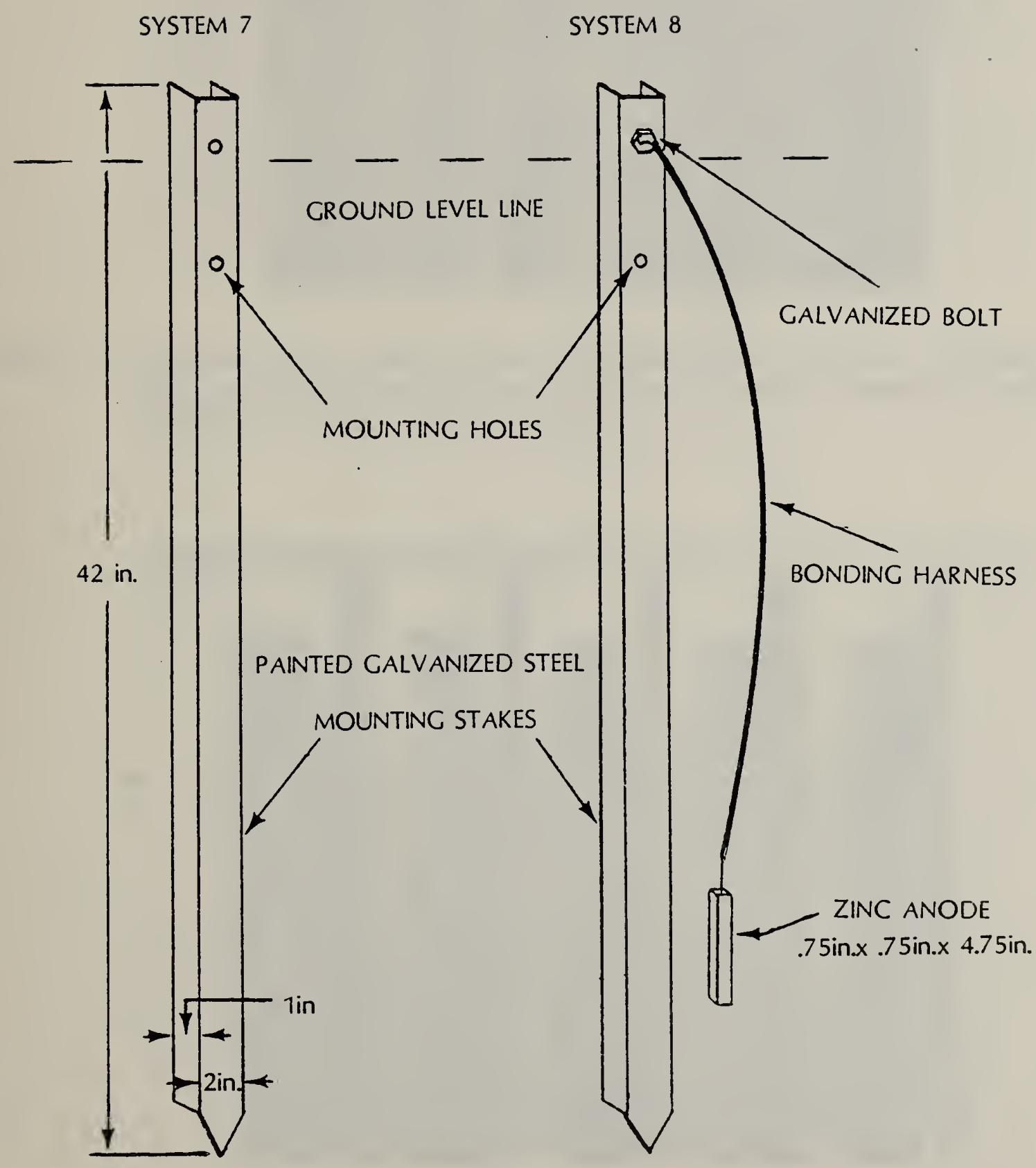

Figure 3 Preparation of mounting stakes for Systems 7 and 8 before exposure test. 



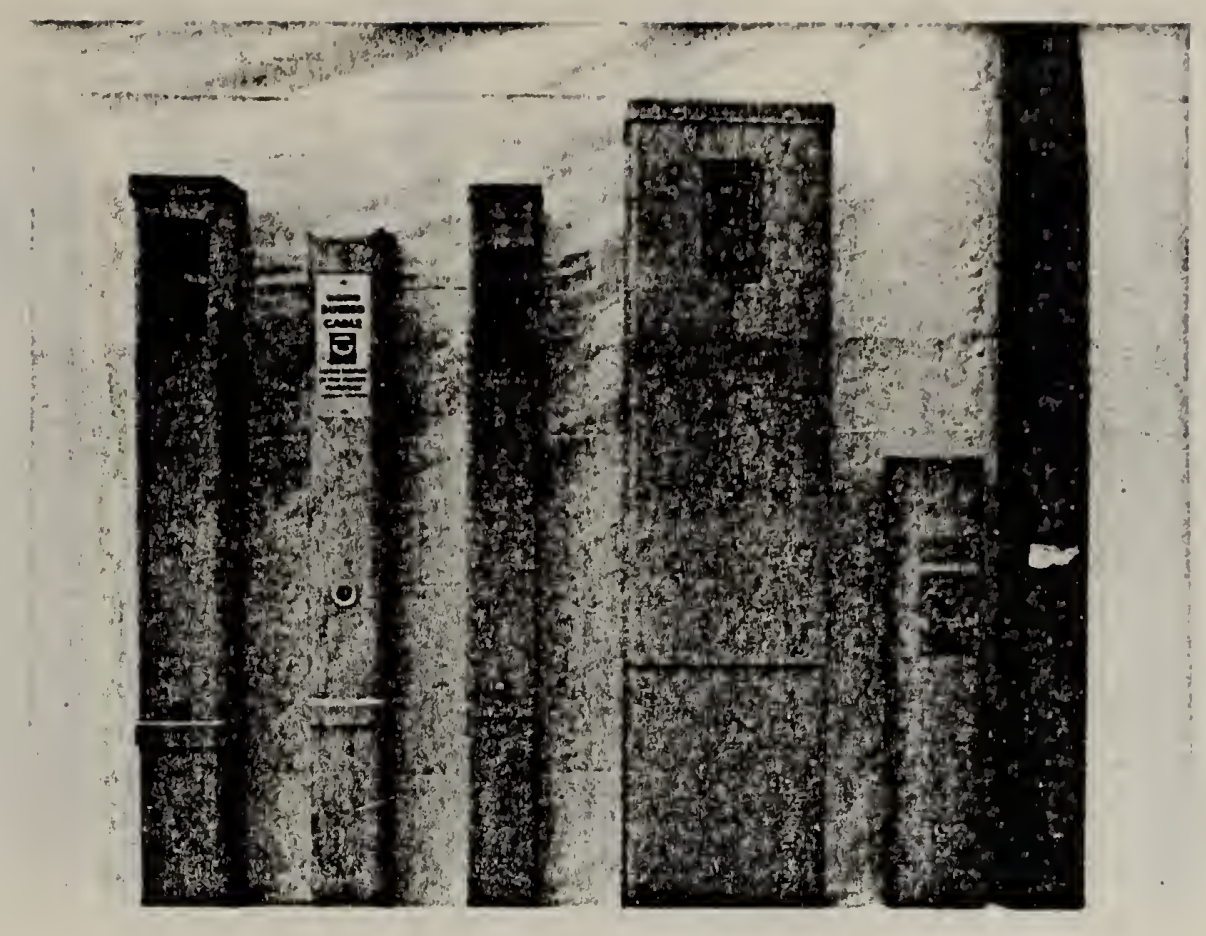

Figure 4. Systems $1,2,3,4$, and 5 , left to right. These pedestal specimens were considered unaffected by corrosion and/or degradation after exposure for one year at site $A$.

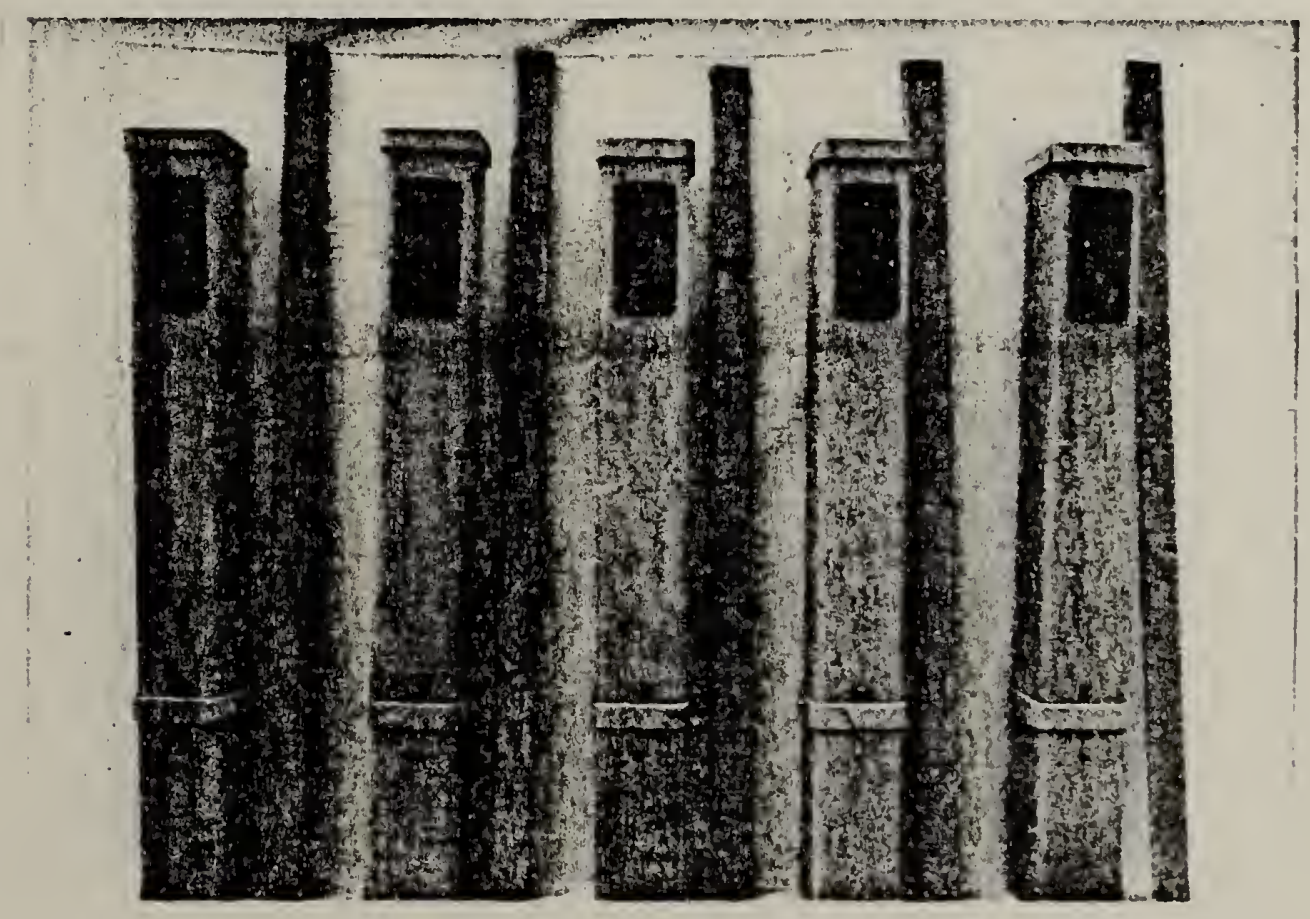

Figure 5. System 1 , sites $B, C, G, H$, and $I$, left to right, exposed for six years. Moderate degradation of the fiberglass surface on the cover plate was observed on all specimens. 



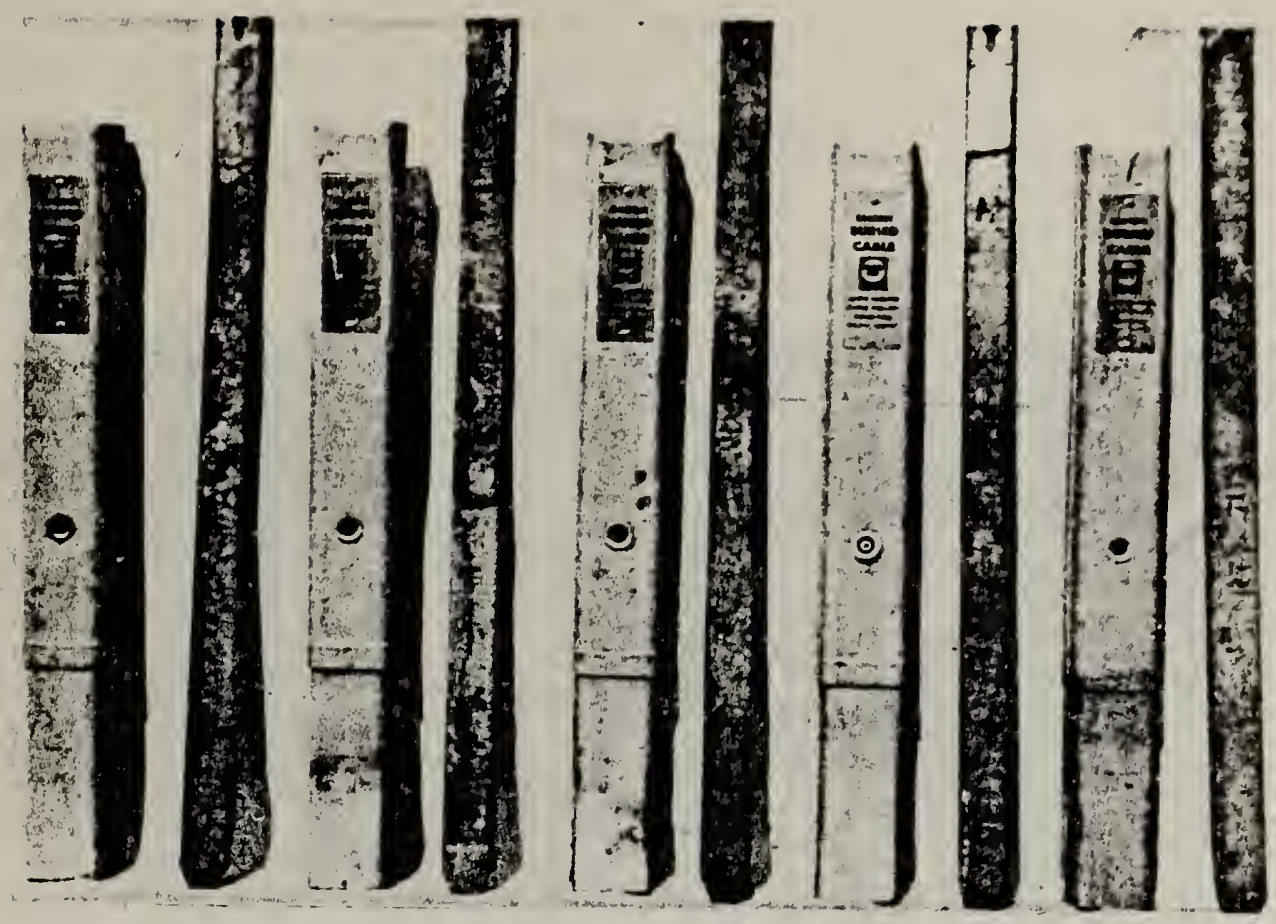

Figure 6. System 2, Sites $B, C, G, H$, and $I$, left to right, exposed for six years. Moderate to severe degradation of the fiberglass surface on the cover plate, cover plate cap, and back plate above ground level on specimens at Sites B,C,H, and I. Dark areas indicate corrosion of the mounting stakes a sites $C$ and $G$.

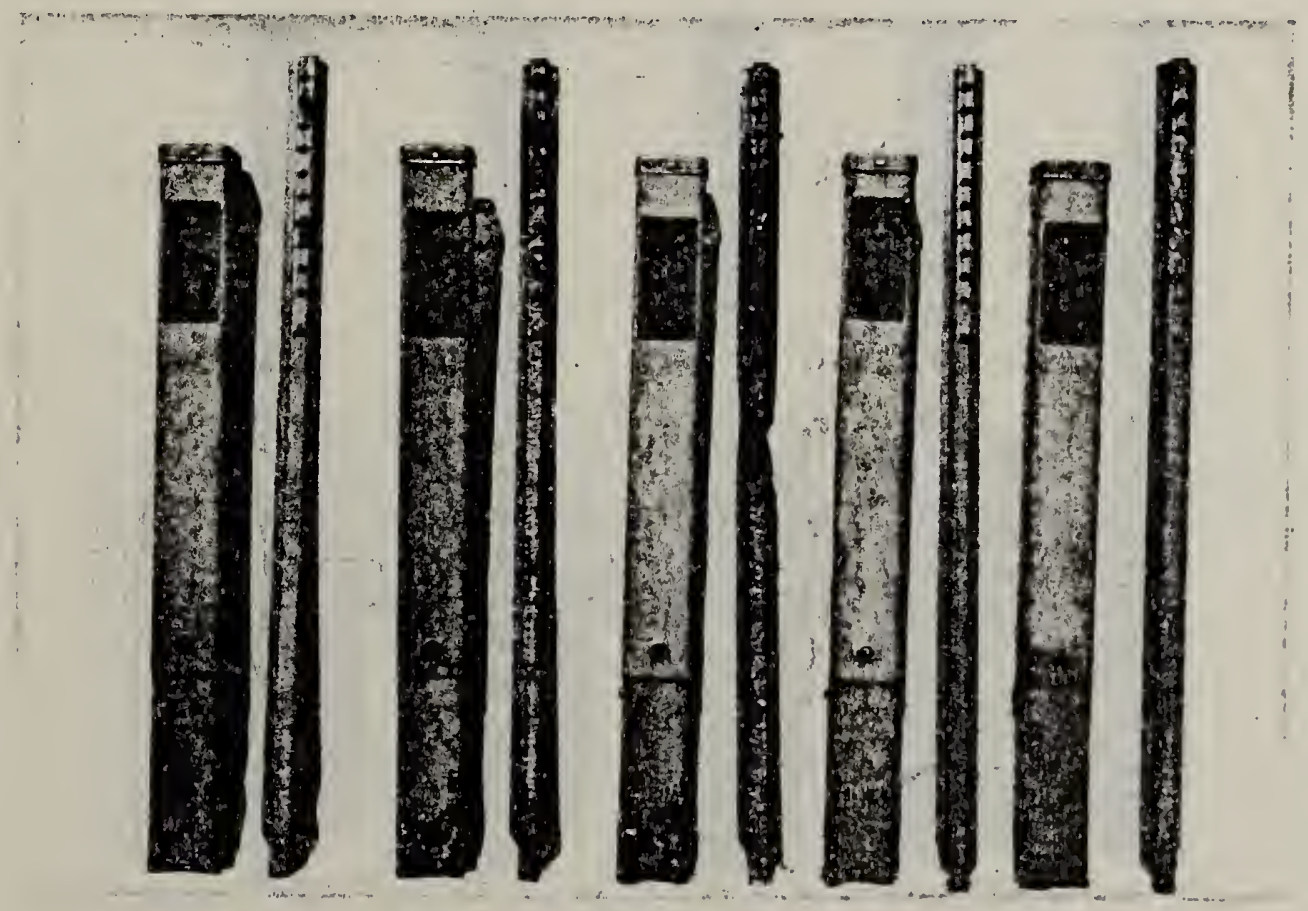

Figure 7. System 3 , Sites $B, C, G, H$, and I, left to right, exposed for six years. Dark areas on specimens indicate corrosion on the mounting stake at Site $C$ and the ground cover plate below ground level at Site G. Severe corrosion of the mounting stake below ground level on the specimen at Site $G$. 



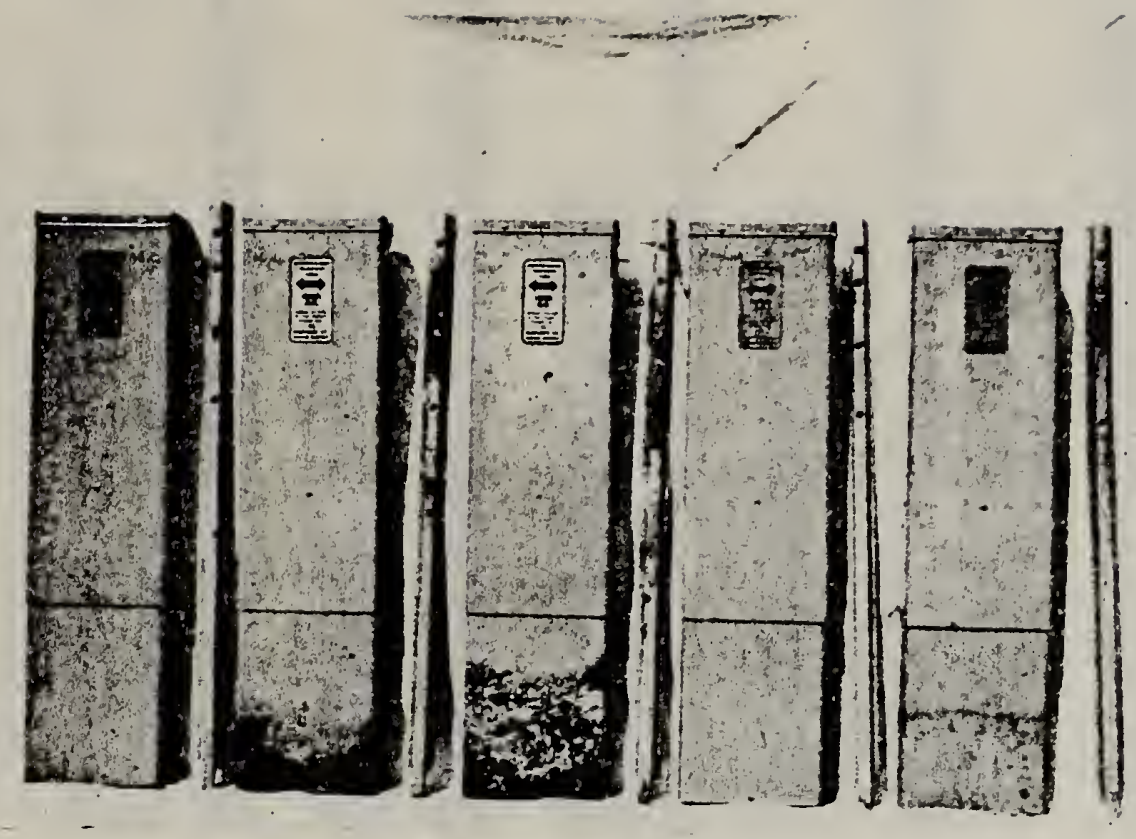

Figure 8. System 4 , Sites $B, C, G, H$, and $I$, left to right, exposed for six years. Dark areas indicate corrosion on the mounting stake and ground cover plate below ground level of the specimen at Site G. The warning sign on the specimen at Site I was not legible.

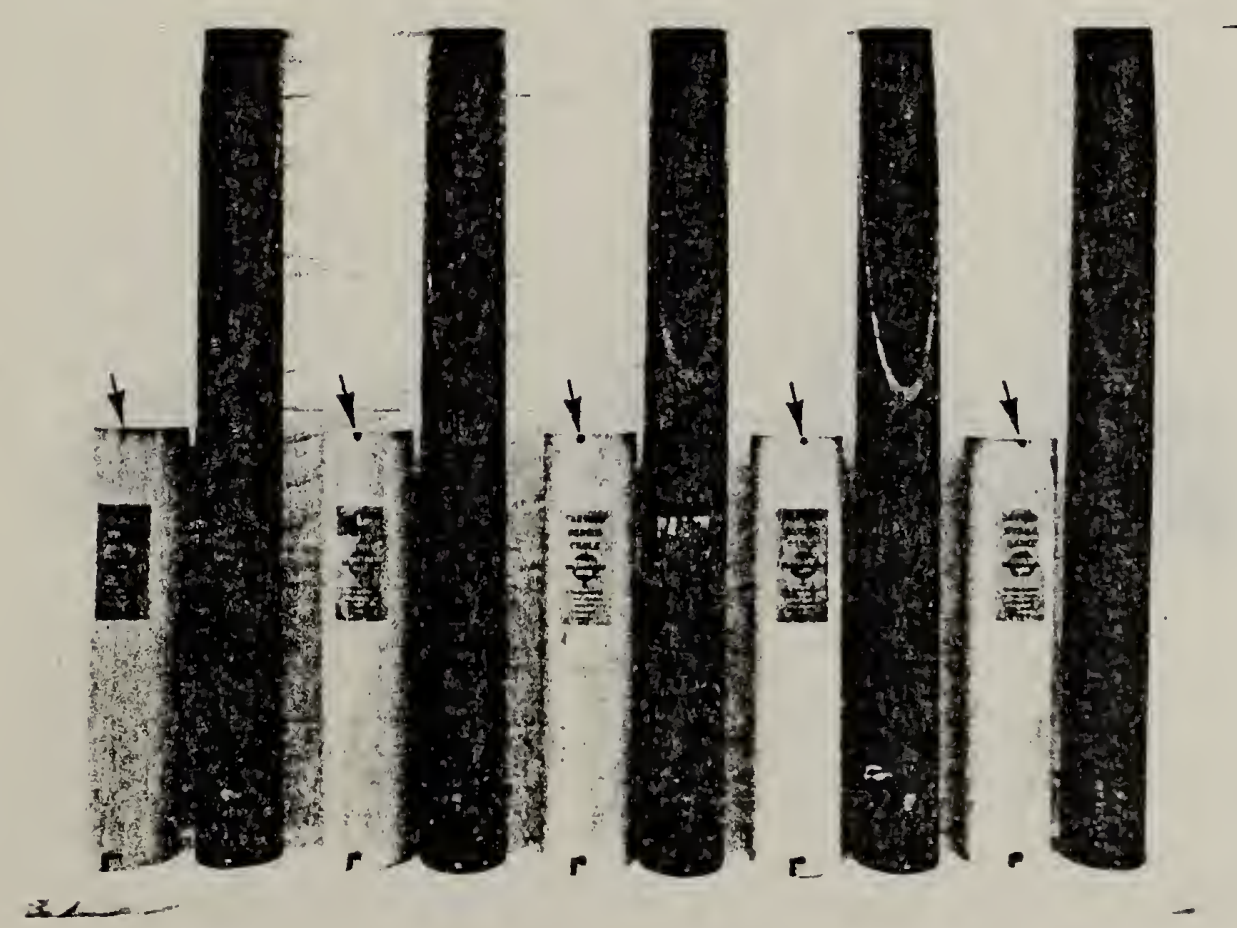

Figure 9. System 5 , Sites $B, C, G, H$, and I, left to right, exposed for six years. Arrows indicate corrosion of the steel rivet on the cover plate cap on all specimens. Streaking of the fiberglass surface on the cover plate of specimens at Sites $B, H$, and I. 



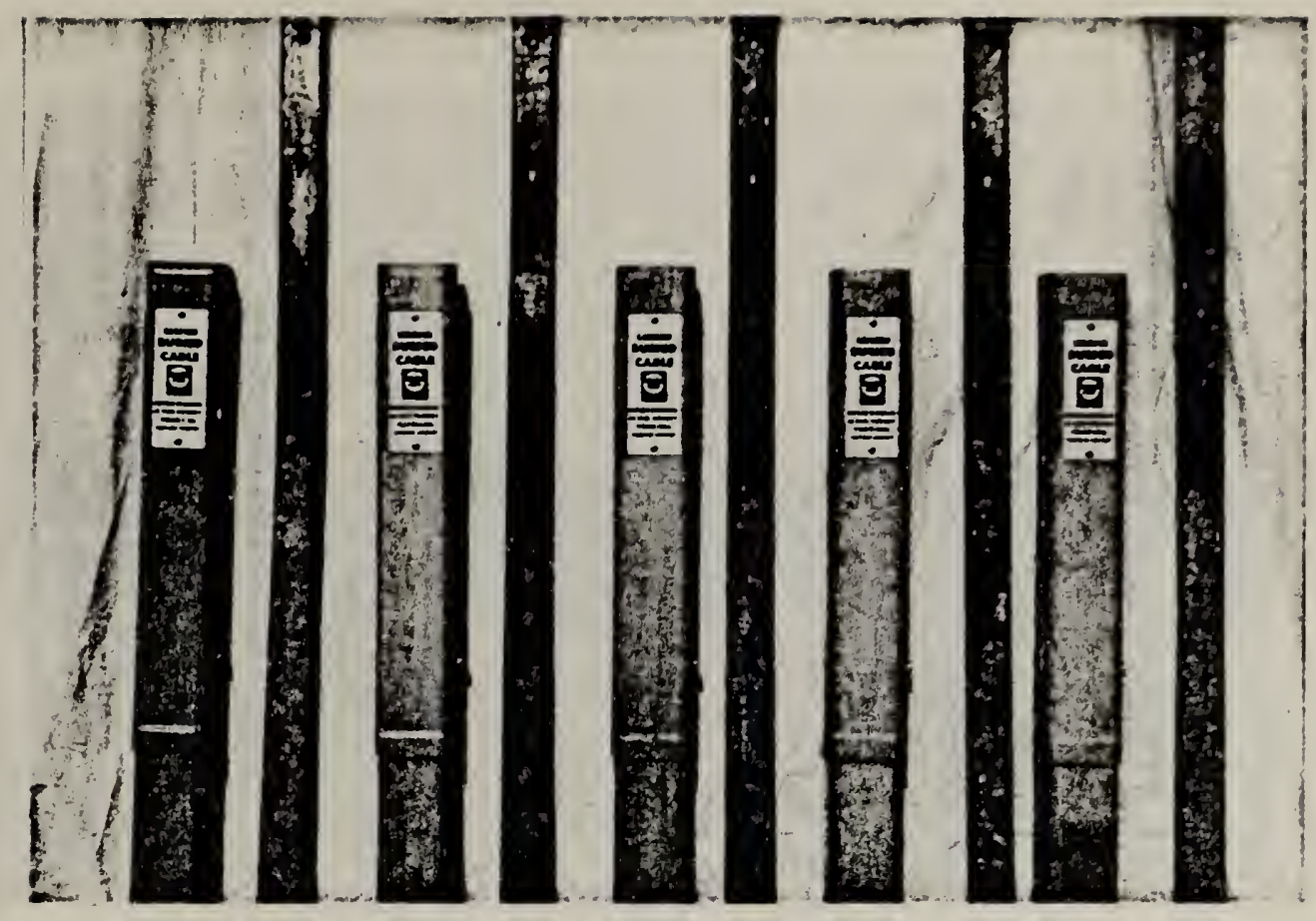

Figure 10. System 6 , Sites $B, C, G, H$, and $I$, left to right, exposed for four years. Slight to moderate degradation of the fiberglass surface on the cover plate and/or cover plate cap on all specimens. Dark areas indicate corrosion on the mounting stake below ground level on specimens at Sites $C$ and $G$.

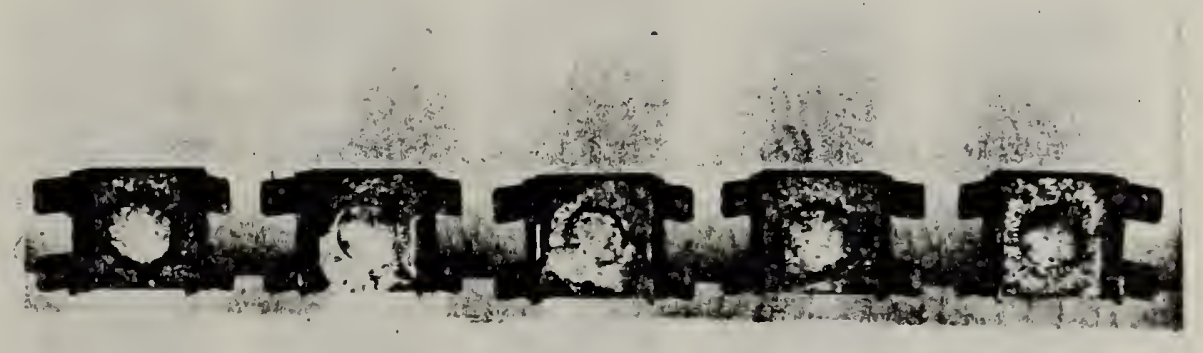

Figure 11. Electrical connector plate and securing hardware of specimens from System 1 , Sites $B, C, G, H$, and I, left to right, exposed for six years. Light areas indicate dissipation of the plated brass connector plate at Sites B and I, while the dark areas indicate the same at Sites $C, G$, and $H$. Light areas on the securing hardware (an aluminum alloy rivet) indicate slight pitting at Sites $C, G$, and $I$. 



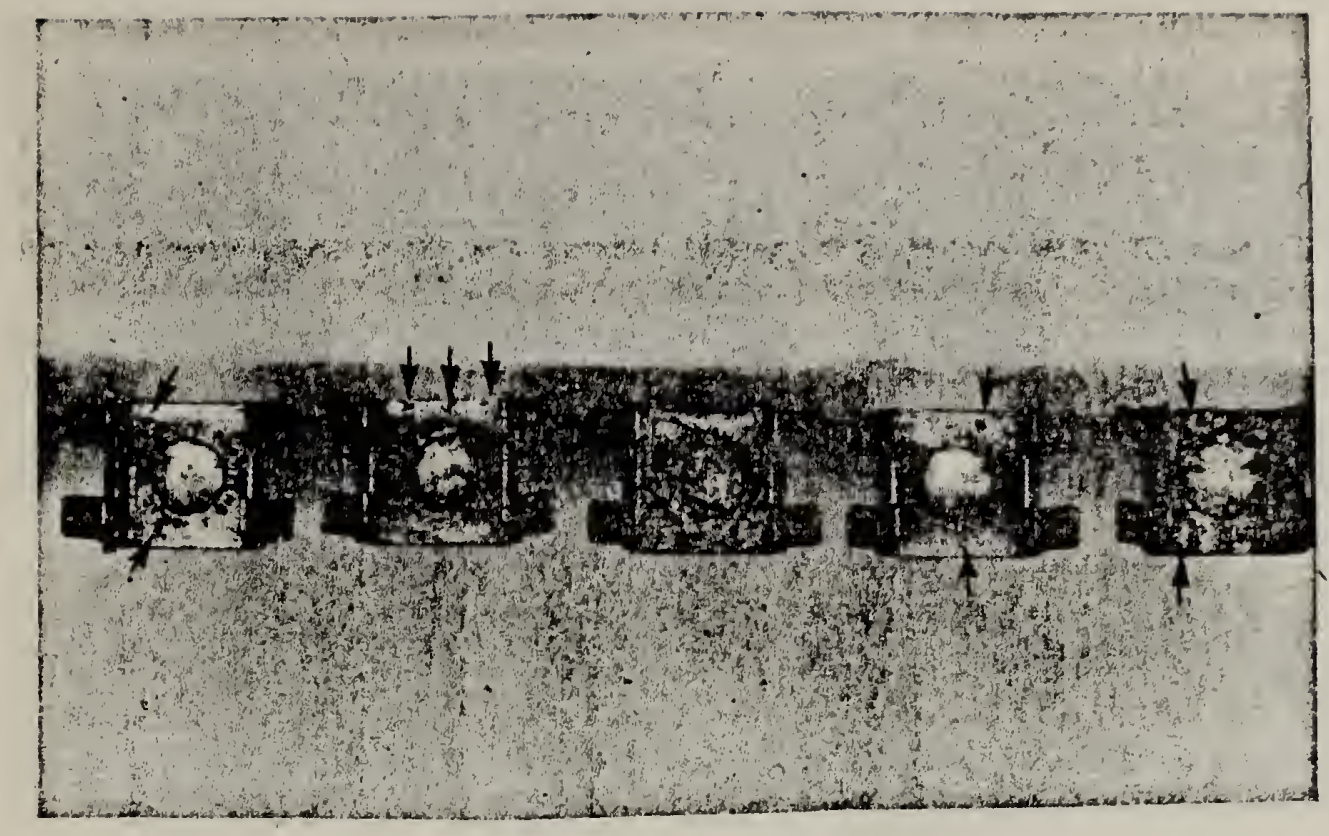

Figure 12. Electrical connector plate and securing hardware of specimens from System 2, Sites $B, C, G, H$, and I, left to right, exposed for six years. Arrows indicate slight corrosion of the plated brass connectors of specimens. Light areas indicate pitting on the securing hardware (an aluminum alloy rivet) of specimens at Sites $C, G$, and $I$.

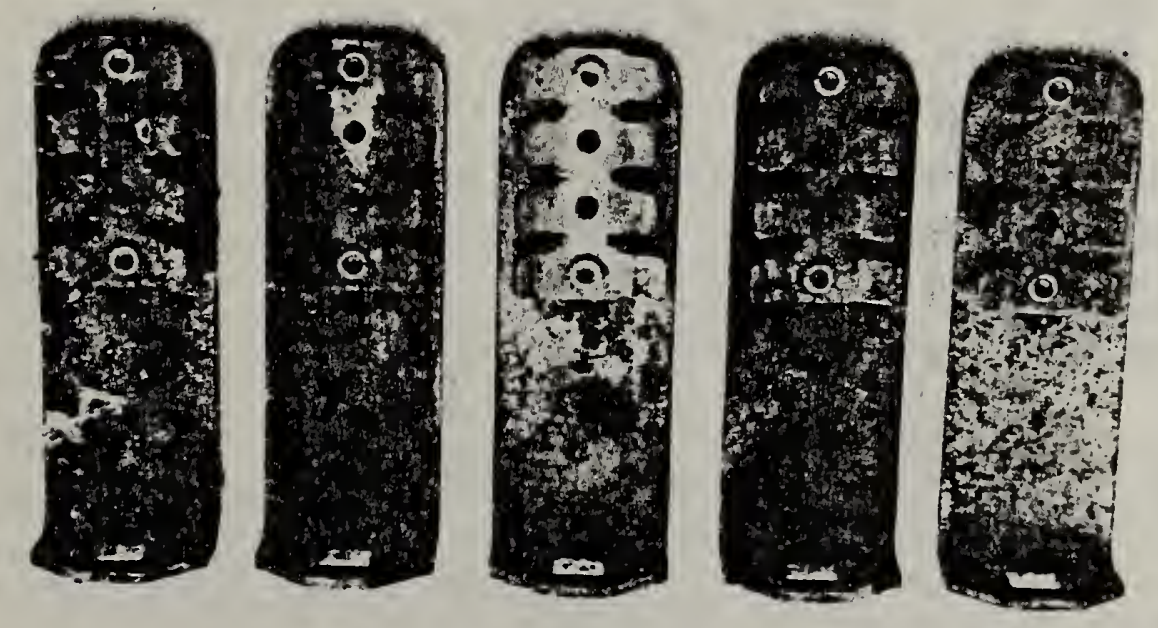

'Figure 13. Electrical connector plate, securing hardware, and bracket of specimens from System 3 , Sites $B, C, G, H$, and I, left to right, exposed for six years. Light areas indicate slight attack of the plated brass connector plate on specimens at sites B,C, $H$, and I. Dark areas indicate slight corrosion of the plated stee 1 bracket on specimens from Sites $B, C, G$, and $I$. 



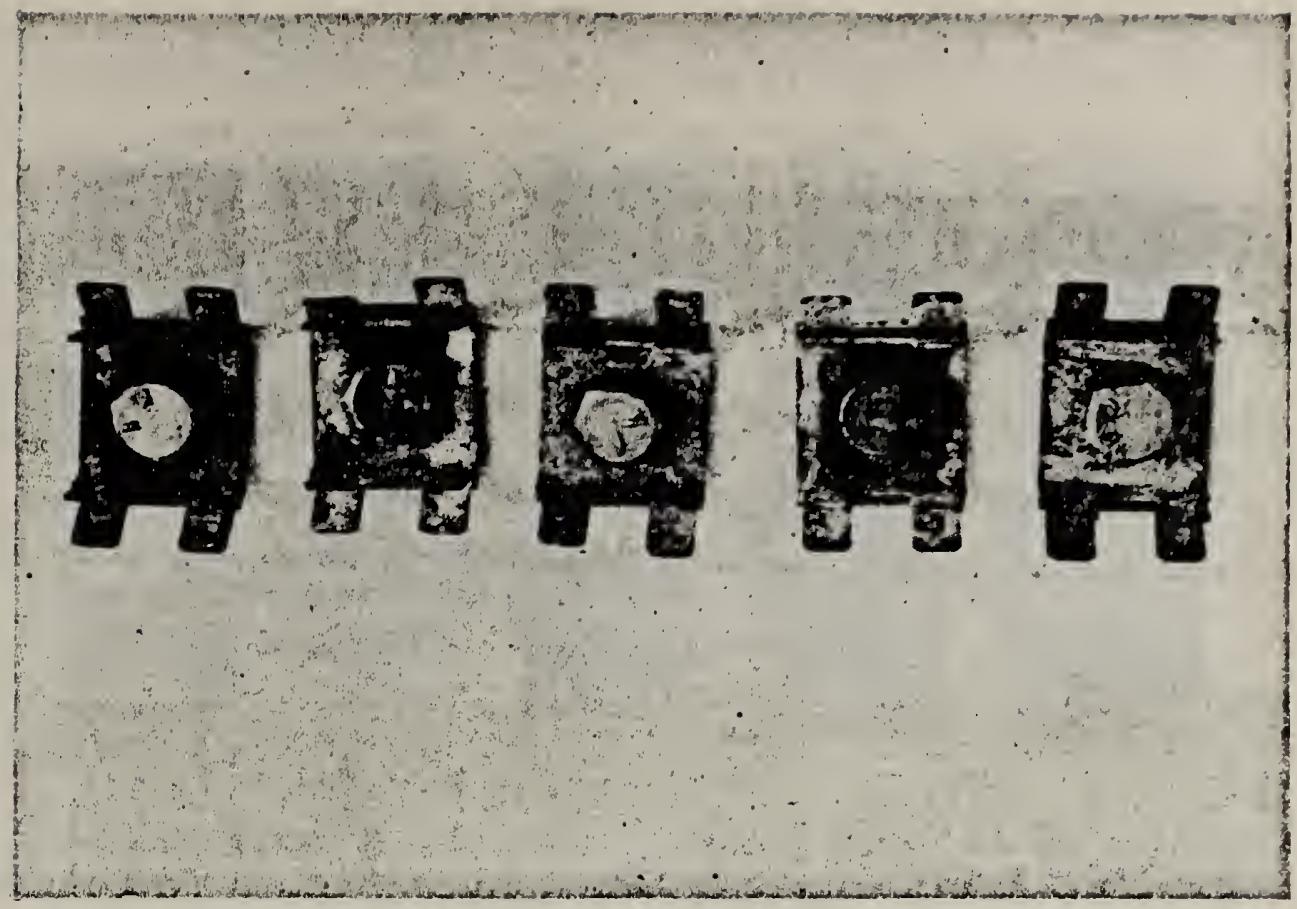

Figure 14. Electrical connector plate and securing hardware of specimens from System 4 , Sites $B, C, G, H$, and I, left to right, exposed for six years. Light areas indicate slight dissipation of the plated brass connector plate on specimens at all sites.

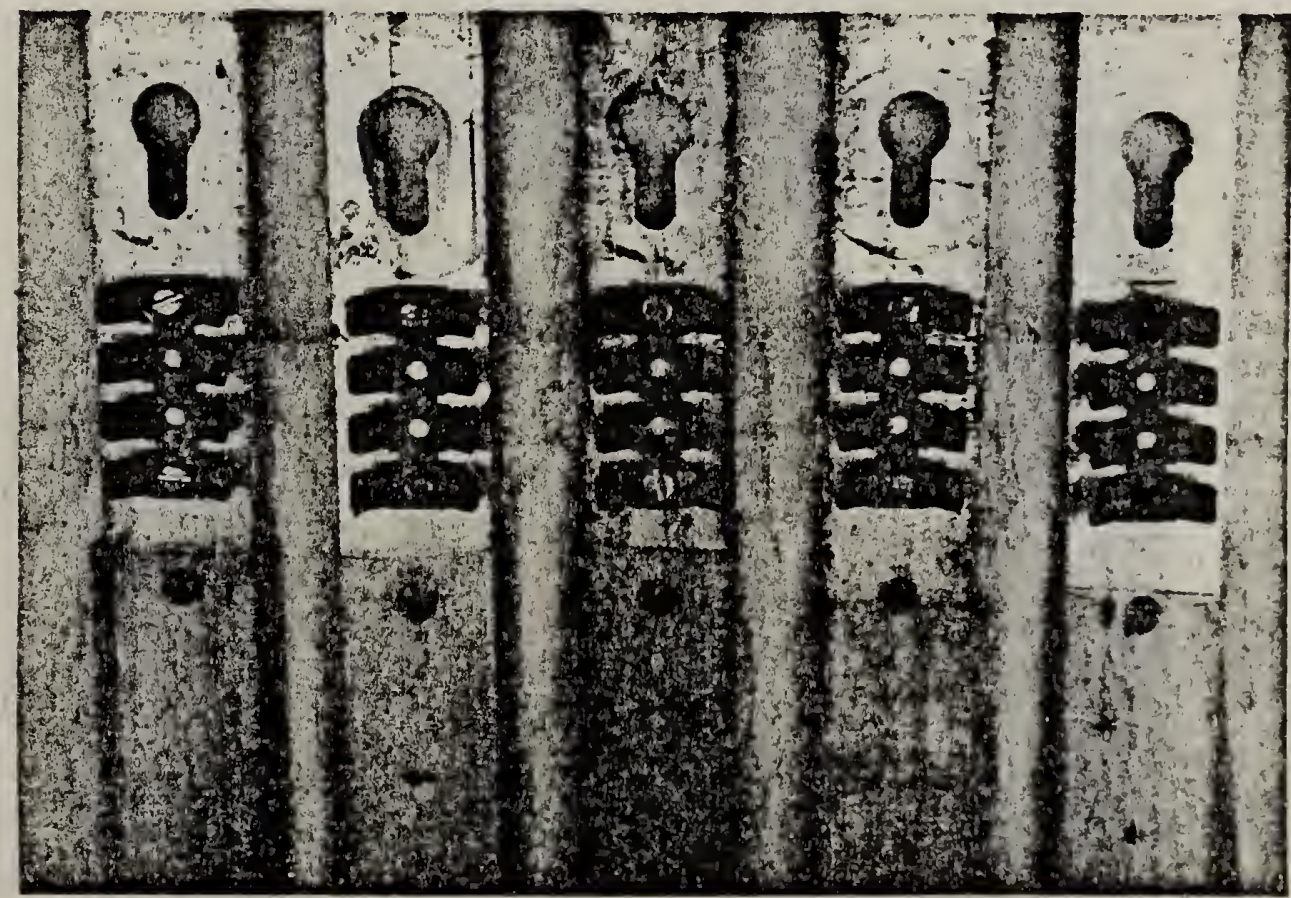

Figure 15. Electrical connector plate, securing hardware, and bracket of specimens from System 5 , Sites $B, C, G, H$, and I, left to right, exposed for six years. Light areas indicate siight corrosion of the plated brass connector plate on specimens at Sites B,C, $H$, and $I$. Dark areas indicate slight corrosion of the securing hardware (a plated steel screw) on the specimen from Site $B$. 



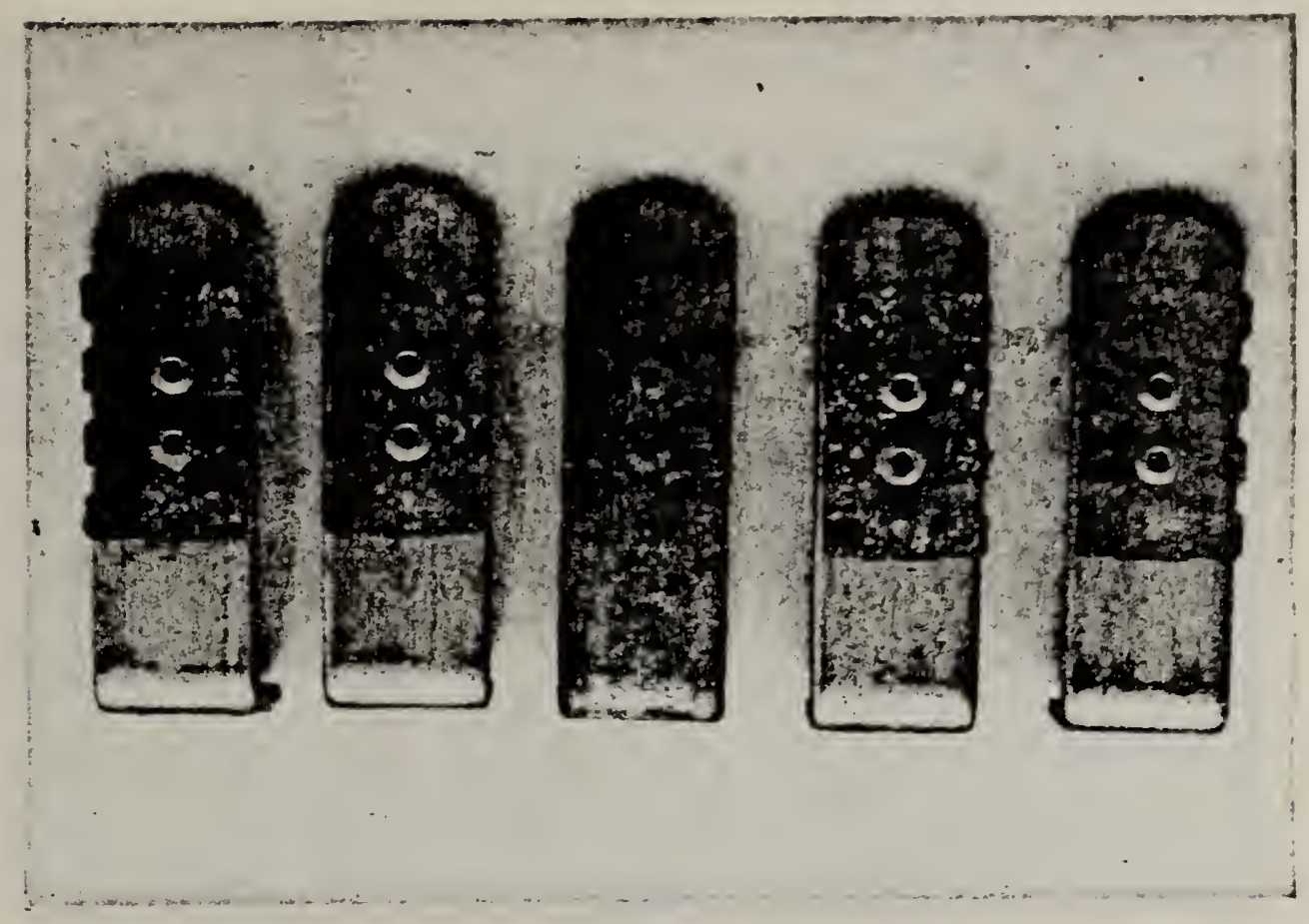

Figure 16. Electrical connector plate, securing hardware, and bracket of specimens from System 6 , Sites $B, C, G, H$, and $I$, left to right, exposed for four years. Light areas indicate slight attack of the plated brass connector plate on specimens at Sites B, C,H, and $\mathrm{I}$. The light areas on the bracket (an aluminum alloy) indicate pitting on specimens at Sites $C, G$, and $I$.

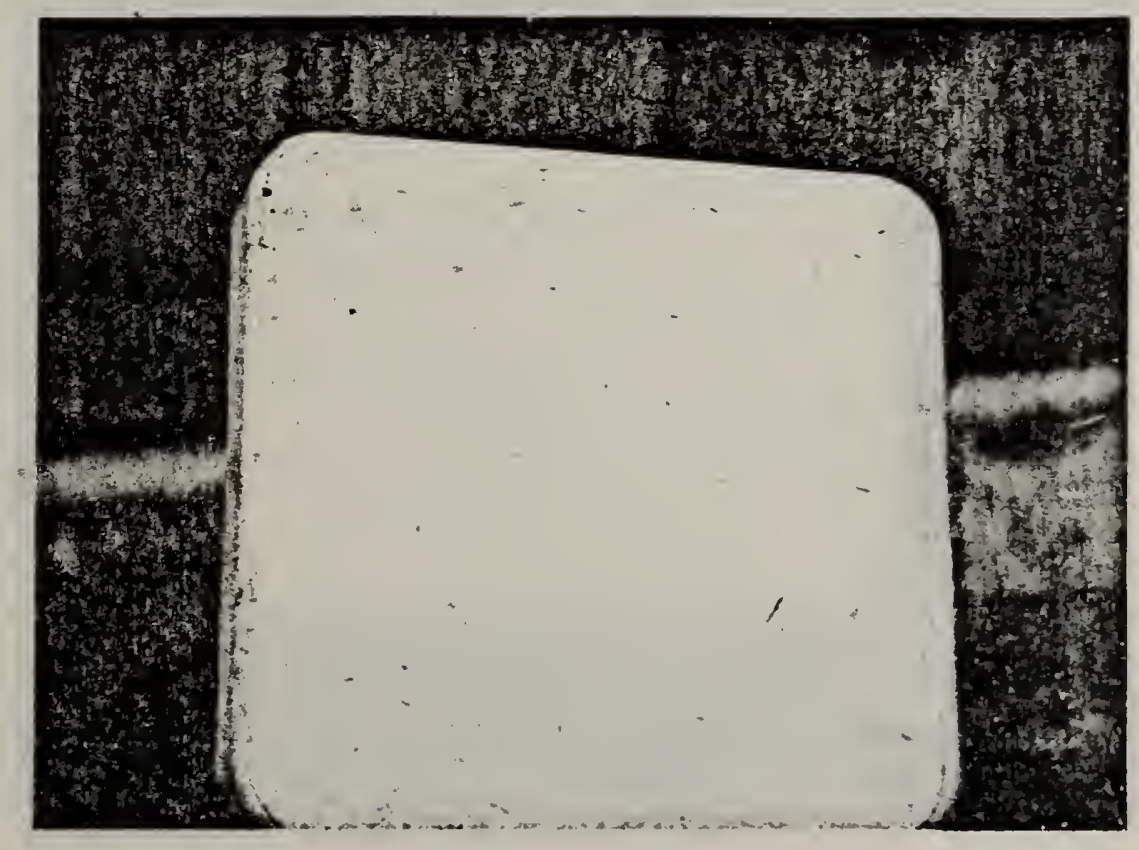

Figure 17. Top view of the cover plate cap of the specimen from System 1 exposed for six years at Site I. Severe degradation of the fiberglass surface. Light areas indicate strands of fiberglass standing out from the resin. 



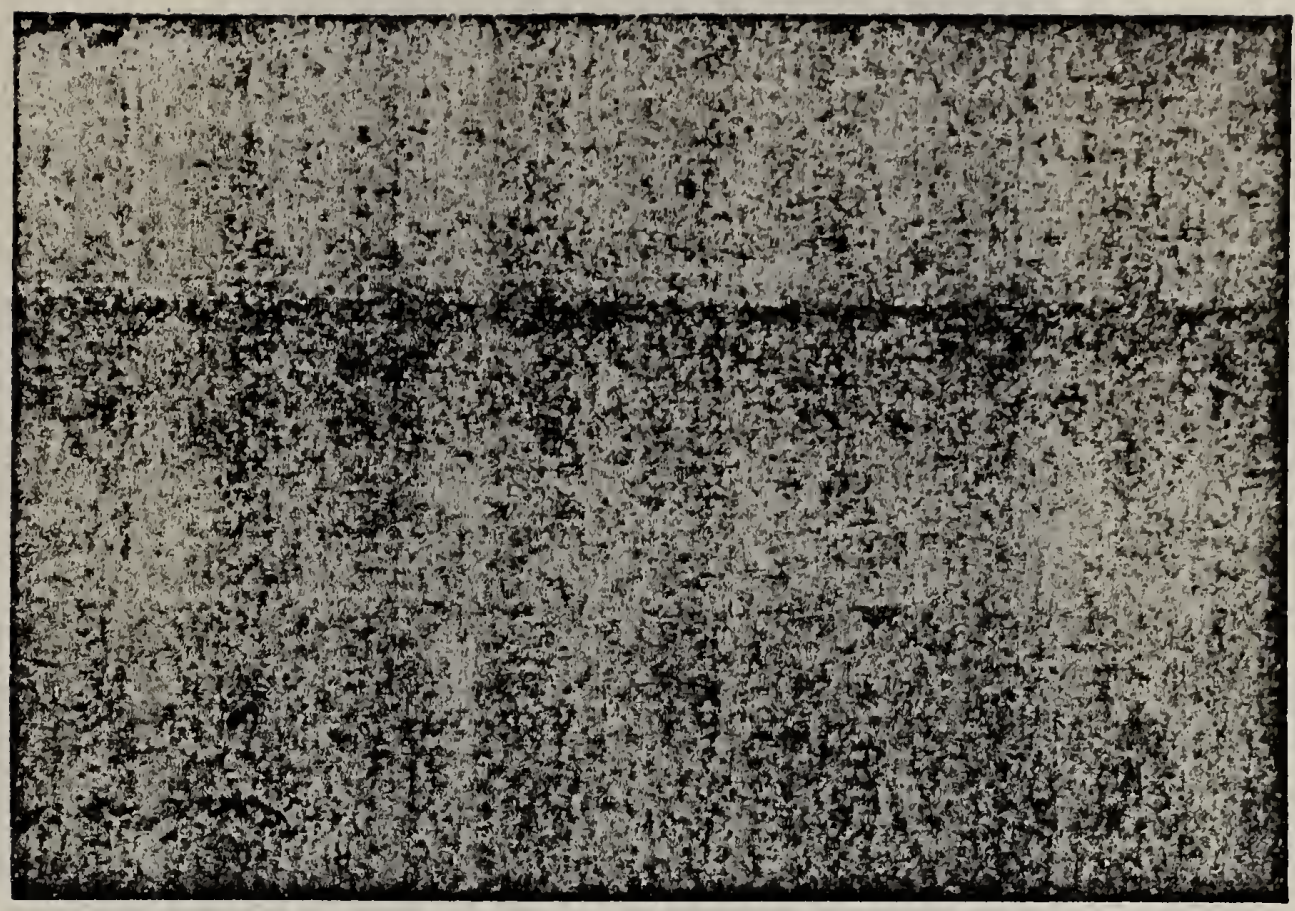

Figure 18. Section of the back plate above ground level of the specimen from System 1 exposed for six years at Site $H$. Dark lines indicate cracking of the fiberglass surface from $0.060 \mathrm{in}$. to $0.370 \mathrm{in}$. in length.

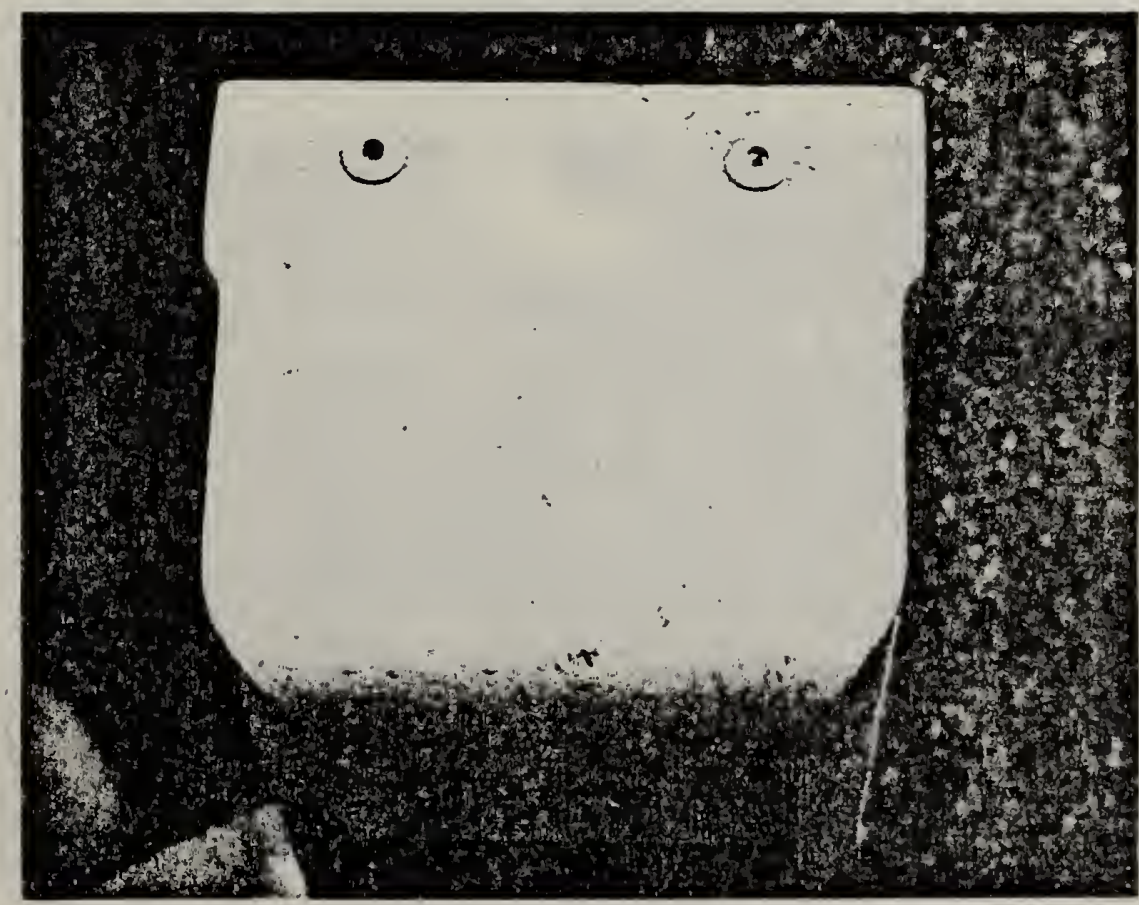

Figure 19. Top view of the cover plate cap of the specimen from System 2 exposed for six years at Site I. Severe degradation of the fiberglass surface. Light areas indicate strands of fiberglass standing out from the resin. 



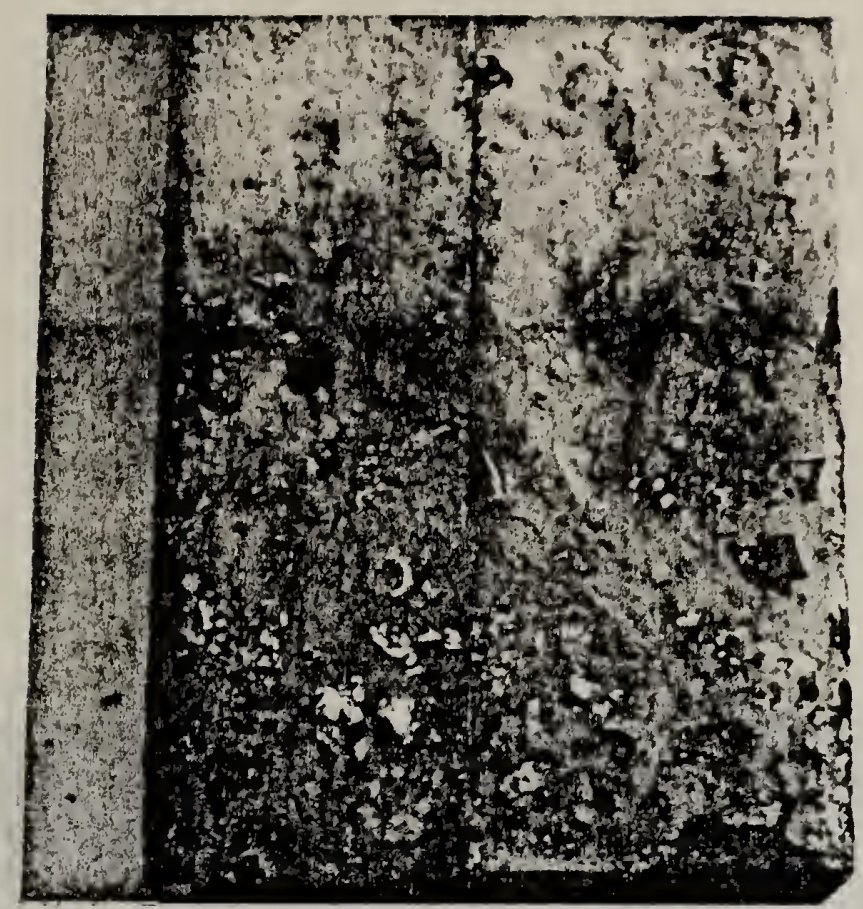

Figure 20. Section of the back plate and ground cover plate below ground level of the specimen from System 3, exposed for six years at Site $G$. Darker areas indicate severe corrosion due to pitting.

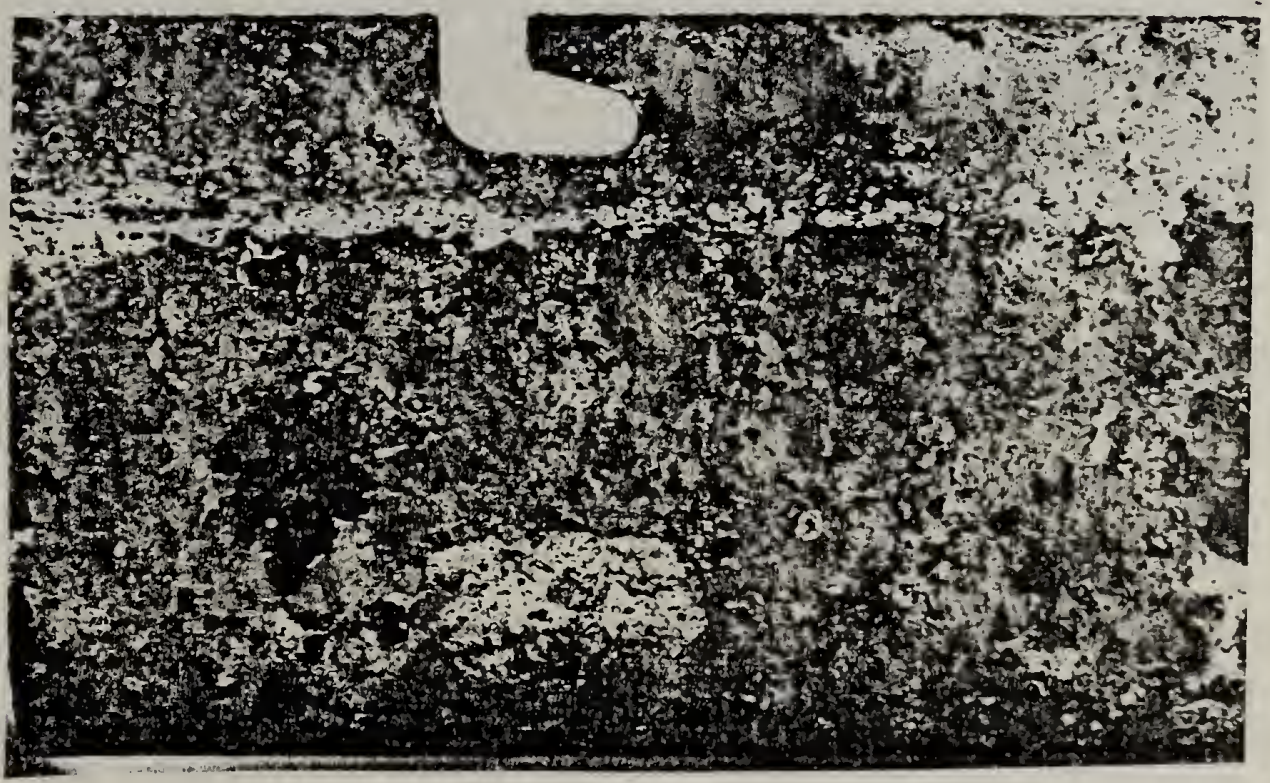

Figure 21. Section of the ground cover plate below ground level of the specimen from System 4 , exposed for six years at Site $G$. Darker areas indicate severe corrosion due to pitting. 



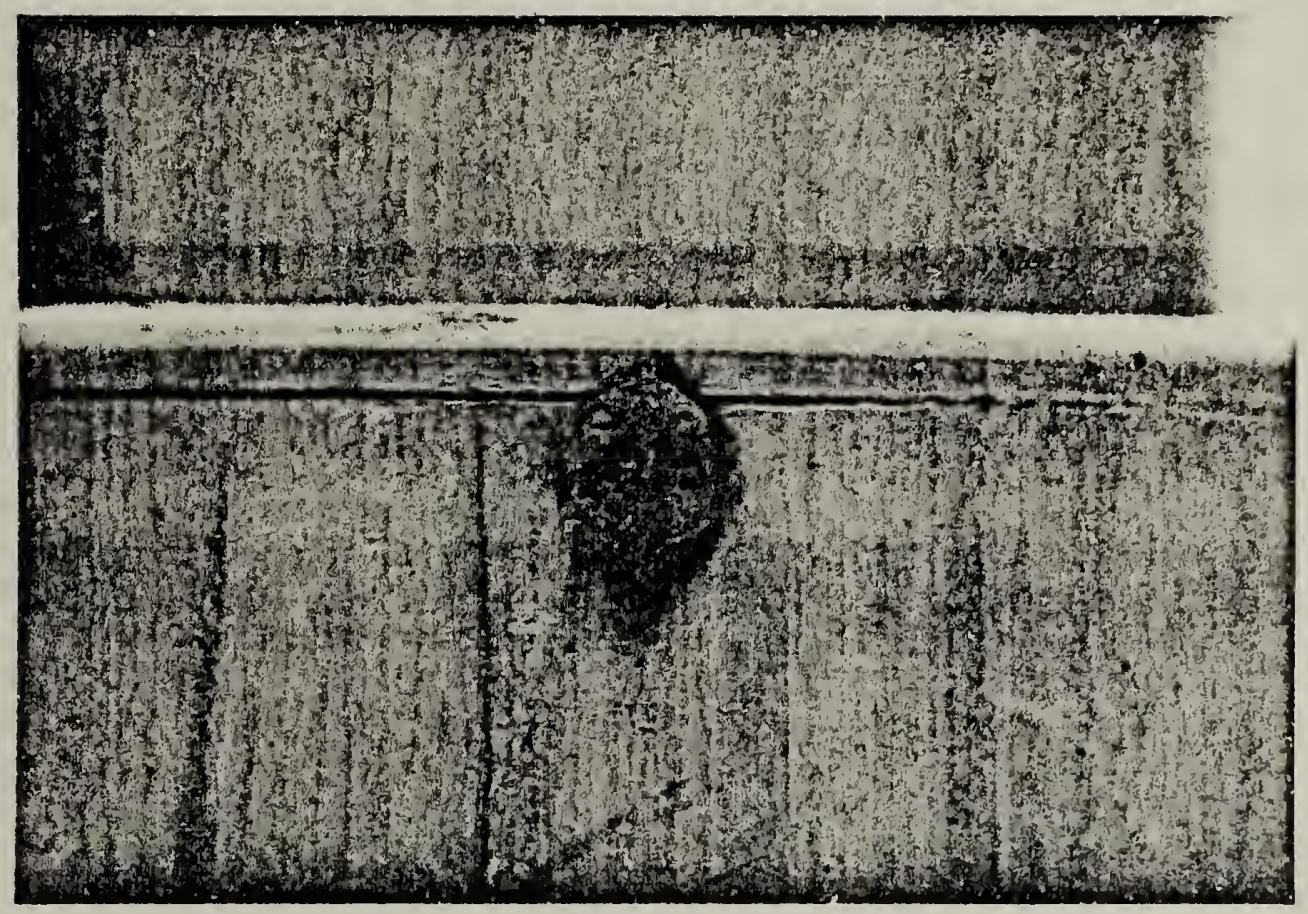

Figure 22. Steel rivet of the cover plate cap of the specimen from System 5 exposed for six years at Site G. Severe corrosion due to pitting can be observed. 

NBS.114A \{REV. 2-BC\}

U.S. DEPT. OF COMM.

BIBLIOGRAPHIC DATA

SHEET (See instructions) 1. PUBLICATION OR
REPORT NO.

NBSIR $84-2810$
2. Performing Organ. Report Nof 3. Publication Date

January 1984

4. TITLE AND SUBTITLE

PERFORMANCE EVALUATION OF TELEPHONE CABLE PEDESTALS IN UNDERGROUND AND

ATMOSPHERIC ENVIRONMENTS

5. AUTHOR(S)

J. L. Fink and E. Escalante

6. PERFORMING ORGANIZATION (If joint or other than NBS, see instructions)

7. Contract Grant No.

NATIONAL BUREAU OF STANDARDS

DEPARTMENT OF COMMERCE

8. Type of Report \& Period Covered

WASHINGTON, D.C. 20234

9. SPONSORING ORGANIZATION NAME AND COMPLETE ADDRESS (STreet. City, StOTE, ZIP)

Rural Electrification Administration

Department of Agriculture

Washington, DC 20250

10. SUPPLEMENTARY NOTES

Document describes a computer program; SF-185. FIPS Software Summary, is attached.

11. ABSTRACT (A 200-word or less factual summary of most significant information. If document includes a significant bibliography or literoture survey. mention it here)

Data are given on the corrosion of the metal surfaces and on the degradation of the fiberglass surfaces of the housing, mounting stake and interral and external hardware of telephone cable pedestals. The materials investigated on were exposed for periods up to six years in six different soil and atmospheric environments. Specimens were exposed as either a painted galvanized steel housing with a painted galvanized steel mounting stake, a painted galvanized steel housing with an unpainted galvanized steel mounting stake, a fiberglass housing with a fiberglass mounting stake, a fiberglass housing with an unpainted galvanized mounting stake, or a fiberglass housing with a polyvinylchloride mounting stake. Metals studied included, aluminum, galvanized steel, plated brass, plated steel, steel, and stainless steel alloys.

12. KEY WOROS (Six to twelve entries; alphabetical order; capitalize only proper names; and separate key words by semicolons)

Alloys; atmospheric; corrosion; degradation; dissipation; fiberglass; painted; pedestals; surface; underground; unpainted;

13. AVAILABILITY

X Unlimited

For Official Distribution. Do Not Release to NTIS

Order From Superintendent of Documents, U.S. Government Printing Office, Washing:on, D.C. 20402.

W Order From National Technical Information Service (NTIS), Springfield, VA. 2216I

14. NO. OF

PRINTED PAGES

59

15. Price 


